\title{
Concentración, segregación y movilidad residencial de los extranjeros en Barcelona ${ }^{1}$
}

\author{
Jordi Bayona i Carrasco ${ }^{2}$ \\ Universitat de Barcelona. Departament de Geografia Humana \\ jordibayona@ub.edu
}

Antonio López $\mathrm{Gay}^{3}$

Centre d'Estudis Demogràfics

tlopez@ced.uab.es

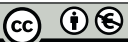

Recepción: julio de 2010

Aceptación: marzo de 2011

\section{Resumen}

El artículo analiza la dinámica residencial de la población extranjera en la ciudad de Barcelona, considerando tres aspectos que centran su distribución: la concentración en el territorio, la segregación residencial en relación con la población de la ciudad y la movilidad residencial en interrelación con su región metropolitana. Se realiza un análisis temporal que sigue la evolución de estos elementos a lo largo de la década, con el objetivo de aportar una visión de conjunto de los cambios observados. El análisis contempla la utilización de diferentes fuentes estadísticas y detalla el comportamiento de las nacionalidades con más efectivos en Barcelona. Los resultados indican un desplazamiento de las áreas de concentración desde el centro histórico hacia la periferia de la ciudad, un descenso de la segregación vinculado a una mayor dispersión territorial y una fuerte movilidad residencial dentro de la Región Metropolitana que afecta especialmente a los municipios situados en la periferia más próxima a la ciudad.

Palabras clave: migración internacional; Barcelona; concentración; segregación espacial; movilidad residencial; Región Metropolitana.

1. Este texto es producto de los proyectos de $\mathrm{I}+\mathrm{D}$ La sostenibilidad social según las formas urbanas: movilidad residencial, espacios de vida y usoO del tiempo en las regiones metropolitanas (2007-2010) (SEJ2007-67948), dirigido per la Dra. Anna Alabart, y La movilidad geográfica de la población extranjera en España: factores sociodemográficos y territoriales (SEJ2007-61662/ GEOG), dirigido por el Dr. Joaquín Recaño y financiado por el Ministerio de Educación y Ciencia en el Plan I+D+I 2004-2007.

2. Jordi Bayona i Carrasco es investigador del Departamento de Geografía Humana de la Universidad de Barcelona, contratado mediante una beca Juan de la Cierva del Ministerio de Ciencia e Innovación, programa cofinanciado por el Fondo Social Europeo.

3. Antonio López Gay es investigador del Centre d'Estudis Demogràfics, contratado mediante una beca Juan de la Cierva del Ministerio de Ciencia e Innovación, programa cofinanciado por el Fondo Social Europeo. 
Resum. Concentració, segregació i mobilitat residencial dels estrangers a Barcelona

L'article analitza la dinàmica residencial de la població estrangera a la ciutat de Barcelona, considerant tres dels aspectes que en centren la distribució: la concentració en el territori, la segregació residencial en relació amb la població de la ciutat i la mobilitat residencial en interrelació amb la seva regió metropolitana. S’hi realitza una anàlisi temporal que ressegueix l'evolució d'aquests elements al llarg de la darrera dècada, amb l'objectiu d'aportar una visió de conjunt dels canvis observats. L'estudi contempla la utilització de diferents fonts estadístiques i detalla el comportament de les nacionalitats amb més efectius a Barcelona. Els resultats indiquen un desplaçament de les àrees de concentració des del centre històric cap a la periferria de la ciutat, un descens de la segregació lligat a una dispersió territorial més gran i una forta mobilitat residencial dins de la Regió Metropolitana que afecta especialment els municipis situats a la periferia més pròxima a la ciutat.

Paraules clau: migració internacional; Barcelona; concentració; segregació espacial; mobilitat residencial; Regió Metropolitana.

\section{Résumé. Concentration, ségrégation et mobilité résidentiel des étrangers à Barcelone}

L'article analyse la dynamique résidentielle de la population étrangère dans la ville de Barcelone en se concentrant sur trois aspects de sa distribution : la concentration sur le territoire, la ségrégation et la mobilité résidentielle au sein de la région métropolitaine. L'évolution de ces trois facteurs a été suivie pendant une décennie dans le but d'obtenir une vision globale des changements observés. Diverses sources statistiques qui détaillent le comportement des populations les plus nombreuses habitant Barcelone ont été utilisées. Les résultats montrent un déplacement des zones de concentration des étrangers depuis le centre historique vers les périphéries, une diminution de la ségrégation due à la croissante dispersion territoriale, et finalement une forte mobilité résidentielle dans la Région Métropolitaine, particulièrement dans les communes les plus proches de Barcelone.

Mots clé: migration internationale; Barcelone; concentration; ségrégation et mobilité résidentielle; Région Métropolitaine.

Abstract. Foreigners' residential behaviour in Barcelona: concentration, segregation and residential change

Three aspects of foreigners' residential mobility in the city of Barcelona are studied in this paper: territorial concentration, segregation and residential change within the metropolitan region. To obtain a global view, these three elements are followed for a decade. Several data bases, specifying the behaviour of major nationalities, are used. Results firstly show that foreigners are gradually moving out of the historical centre and into the periphery. Secondly, that there is a strong intra-metropolitan mobility, particularly so in the municipalities nearest to the central city. Finally, as foreigners are more widely distributed throughout the territory, they are also becoming less segregated.

Key words: international migration; Barcelona; concentration; segregation and residential mobility; Metropolitan Region. 


\section{Sumario}

$\begin{aligned} & \begin{array}{r}\text { Introducción } \\ \text { La segregación residencial } \\ \text { en las ciudades de España }\end{array} \begin{array}{l}\text { La concentración y la segregación } \\ \text { Ln territorio }\end{array} \\ & \begin{aligned} \text { Fuentes estadísticas utilizadas residencial de la población } \\ \text { de nacionalidad extranjera }\end{aligned} \\ & \begin{aligned} \text { La evolución de la inmigración } \\ \text { internacional en Barcelona }\end{aligned} \text { Referencias bibliográficas }\end{aligned}$

\section{Introducción}

La llegada y el progresivo asentamiento, en un corto periodo temporal, de aproximadamente trescientos mil nuevos residentes con nacionalidad extranjera, ha constituido el mayor impacto sobre la dinámica poblacional de la ciudad de Barcelona, que, después de veinte años de pérdida continuada de población debido a la suburbanización residencial, vuelve a recuperar población. Más allá de su efecto sobre la dinámica demográfica, la inmigración internacional ha impactado notablemente en la composición social de una ciudad que, en la actualidad, es mucho más diversa y compleja, especialmente si tenemos en cuenta que casi un $18 \%$ de su población es de nacionalidad extranjera (y un $21 \%$ es nacida en el extranjero).

Además, y en contraste con otras ciudades europeas con mayor experiencia en la llegada de extranjeros, la inmigración que recibe la ciudad se caracteriza por una elevada heterogeneidad en sus orígenes, diversidad reflejada también en su composición por sexo y edad. Esta situación, característica de las migraciones internacionales del siglo XXI, incide en su presencia en el territorio, ya que coexisten simultáneamente pautas residenciales diversas que incluso llegan a ser contrapuestas. Es este último aspecto, la implantación de la población extranjera en los barrios de la ciudad, el que aquí se estudiará, considerando la perspectiva temporal que los datos estadísticos españoles ofrecen, para observar un periodo marcado por la aceleración de los flujos migratorios internacionales, caracterizados por su inusitada intensidad.

Debido a este último aspecto, no se considera la utilización en profundidad del censo de población de 2001, que, aunque permitiría analizar las características sociodemográficas de la población al mismo tiempo que su distribución en el territorio, no recoge el periodo de máximo crecimiento de la población extranjera en España. La atención del artículo se centrará en la inserción territorial de esta población en la ciudad de Barcelona considerando dos aspectos: 1) los cambios en la distribución territorial de la población extranjera a escala intraurbana, y 2) el estudio de la movilidad residencial de la población extranjera en el ámbito metropolitano. Esta doble perspectiva nos permitirá comprender mejor las dinámicas espaciales de la población extranjera en Barcelona, dominadas por la dispersión, ya sea producida dentro o fuera de los límites de la ciudad. Consideramos que la ciudad de Barcelona ha ejercido de punto de 
atracción en la migración internacional, con una función de puerta de entrada de los inmigrantes en el territorio que ha dado paso a una redistribución territorial posterior. Esto mismo ha sucedido a nivel intramunicipal, donde algunos barrios del centro histórico han desarrollado una función similar.

\section{La segregación residencial en las ciudades de España}

Los estudios que han analizado la inserción residencial de la población extranjera en las urbes españolas y sudeuropeas son recientes, y su aparición coincide con el crecimiento de la inmigración internacional en estos países, nuevos receptores de inmigrantes. Varios estudios han considerado los casos de la ciudad de Barcelona (Bayona, 2007; Musterd y Fullaondo, 2008; García-Almirall et al., 2008; Martori y Hoberg, 2004), Madrid (Martínez y Leal, 2008), o la comparación entre ambas, así como los casos de ciudades de menor tamaño, como Bilbao (Lavía, 2008), Sevilla (Díaz, 2009), Palma de Mallorca (Mateu, 2007) o Valencia (Torres, 2002), entre otras muchas. En la mayoría de estos trabajos, se han utilizado alguno de los diversos indicadores que intentan sintetizar la distribución de la población extranjera, siguiendo la larga tradición iniciada ya en los estudios de la escuela de ecología urbana de Chicago. Los resultados, a partir de los datos del censo y del padrón continuo, indican, en general, la existencia de unos valores de segregación generalmente reducidos o relativamente moderados ${ }^{4}$ (alrededor de 0,3 para el conjunto de extranjeros y por debajo de 0,5 en la mayoría de nacionalidades), aunque con diferencias remarcables entre nacionalidades. Así, los latinoamericanos muestran los valores más bajos (en algún caso por debajo de 0,2 ) y los asiáticos, los más elevados (alcanzan incluso el 0,8 ), mientras que la segregación de los africanos (alrededor de 0,5) también es relativamente alta, y moderada la de los europeos comunitarios, los cuales siguen pautas similares a las clases sociales autóctonas con mayores niveles de ingresos. Además, en la mayoría de ocasiones, se constata un descenso paulatino en los índices de segregación (relacionado con el aumento sostenido del número de inmigrantes, pero no como consecuencia de él). Territorialmente, en ciudades como Barcelona, el centro urbano histórico es un lugar de llegada y asentamiento, aunque el patrón que se reproduce más usualmente es la presencia creciente de extranjeros extracomunitarios en los barrios obreros o construidos a remolque de antiguos procesos migratorios internos.

Las diferencias entre nacionalidades en la distribución se explican por varios motivos. Destacan aquellas aproximaciones que inciden en las diferencias socioeconómicas (que explicarían acertadamente la distribución de los extran-

4. Los índices de segregación presentan valores en una escala entre 0 y 1 (o entre 0 y 100). El valor inferior indica la inexistencia de segregación, es decir, que dos poblaciones determinadas se distribuirían de la misma forma en el territorio. El valor máximo responde a la situación de segregación extrema, de forma que esas dos poblaciones no coincidirían en ningún caso sobre el mismo territorio. 
jeros comunitarios), en las características de los inmigrantes (para explicar los valores de los latinoamericanos, a partir de su nivel de estudios o en relación con la actividad), pero también en factores menos cuantificables, como la existencia de discriminación para ciertos colectivos (Checa y Arjona, 2007) o la más difícil preferencia por residir en áreas homogéneas. La discriminación, en relación con la vivienda y especialmente en el alquiler (Bayona, 2007), aparece como un factor clave en la distribución. No obstante, la escasez de vivienda en alquiler puede provocar, como indica Pareja-Eastaway (2009), que el inmigrante acceda a la propiedad cuando su situación laboral lo permita, cambio de tendencia que explicaría las transformaciones observadas en la distribución en los últimos años, que, debe recordarse, coincidieron con el boom inmobiliario español, en que los extranjeros también participaron.

Esta situación descrita a partir de los indicadores, en cambio, no se corresponde con su elevada precariedad residencial, especialmente si tenemos en cuenta que, mayoritariamente, acaban de llegar al país. Así lo comentan Martínez y Leal (2008) para la ciudad de Madrid, o en relación con las características de la vivienda para Barcelona (Bayona, 2007), aunque los datos disponibles sobre las características de las viviendas sean del lejano 2001. Estos argumentos aparecen en los primeros trabajos que comparan varias urbes sudeuropeas (Malheiros, 2002; Arbaci, 2004 y 2008), en los que se considera un modelo residencial que difiere del resto del continente (Musterd et al., 1997) y que afecta a la distribución de los extranjeros residentes. En todo caso, parece ser que los valores de segregación no informan correctamente de la exclusión residencial que viven los inmigrantes. Las diferencias territoriales parecen ser menores que en otras grandes ciudades europeas, mientras que, en cambio, las condiciones de la vivienda, tanto en lo que se refiere a sus características físicas como al grado de ocupación de éstas, reflejan con mayor exactitud la situación de exclusión en que se encuentran.

Por otro lado, cabe considerar la existencia, especialmente desde 2003, de una elevada movilidad residencial entre la población extranjera. En el caso de Barcelona, estos movimientos tienen como destino preferente los propios barrios de la ciudad y la periferia urbana más próxima. Este aspecto, el de la movilidad de la población extranjera, ha sido tratado con profundidad entre provincias españolas (Recaño, 2002; Pumares, García y Asensio, 2006) y, más recientemente, en relación con algunas grandes metrópolis españolas, como en el caso de Barcelona y su región metropolitana (Bayona y López, 2009), donde destaca su elevada intensidad, que se reproduce en la mayoría de edades activas. A nivel intraurbano, por la dificultad de recogida de datos al respecto, existen menos trabajos en el caso español, aunque para Barcelona (Bayona y Pujadas, 2011) se constata esta elevada movilidad, que nos indicaría la existencia de una alta precariedad asociada a una primera etapa de llegada a la ciudad y a su inserción en el mercado inmobiliario. En este sentido, el efecto de esta movilidad sobre los indicadores de segregación sería un aspecto a considerar en futuros trabajos, con un impacto relevante si se tienen en cuenta las altas tasas de movilidad de los extranjeros, tanto dentro de la ciudad como hacia el exterior de ella. 


\section{Fuentes estadísticas utilizadas}

El padrón continuo de población es la principal fuente de datos empleada en este estudio, con datos de población disponibles desde 1998. Para 1996 y 2001, se dispone, además, del padrón de población y del censo. El padrón continuo contabiliza a los habitantes de un municipio, y se configura como el instrumento que, con carácter anual, nos informa de la población oficial. A pesar de su alto grado de actualización, las variables que nos aporta se refieren únicamente a la edad, al sexo y a la nacionalidad del individuo. El padrón se actualiza con las altas y las bajas producidas por los nacimientos, las defunciones y los flujos migratorios. Aunque se trata de un registro municipal, el Instituto Nacional de Estadística (INE) centraliza y depura los datos. Se dispone de información inframunicipal ${ }^{5}$ anualmente desde 2004.

$\mathrm{El}$ análisis de los flujos migratorios metropolitanos se ha realizado a partir de los datos de la Estadística de Variaciones Residenciales (EVR), probablemente una de las fuentes más fiables existentes en el mundo para rastrear los cambios de residencia de la población. La EVR es un subproducto del padrón de población y registra todos los cambios de vivienda que cruzan una frontera municipal en España (con datos sobre el sexo, la edad, la nacionalidad, el país de nacimiento y el municipio de origen y destino del migrante). También registra las altas y las bajas con origen o destino en el extranjero, pero esas relaciones territoriales, que, por otra parte, son las menos fiables, no han sido contempladas en este estudio. Aunque la EVR es una fuente de información con una larga tradición en España, este trabajo se limita a recoger los flujos de los once años del periodo 1998-2008. Sus microdatos proporcionan información demográfica básica del migrante que permite dibujar su estructura por sexo y edad. Por otro lado, el gran detalle geográfico de esta fuente ha permitido analizar las relaciones territoriales de las migraciones que tienen como origen o destino el municipio de Barcelona en el contexto metropolitano. La pequeña extensión territorial de los municipios de la Región Metropolitana de Barcelona es un rasgo positivo para el desarrollo de este trabajo, ya que permite identificar con gran detalle los itinerarios residenciales de la población que cruza los límites del municipio de Barcelona.

\section{La evolución de la inmigración internacional en Barcelona}

En enero de 2009, 284.385 extranjeros residen en la ciudad de Barcelona, una cifra que representa el $17,5 \%$ de su población, que alcanza los 1.621 .537 habitantes. El crecimiento del número de extranjeros empadronados ha sido muy importante en la última década (figura 1). Es a partir de 1999, momento

5. En el análisis a nivel de sección censal, se han obviado los datos de la sección 68, en la cual se sitúa la sede del Departamento de Estadística del Ayuntamiento, ya que existe una fuerte sobrerrepresentación de extranjeros de los que se desconoce el domicilio en la ciudad, y el Ayuntamiento los empadrona en dicha sección. Su perfil responde a una alta presencia de las nacionalidades con flujos más recientes, y varían fuertemente de un año a otro. Alrededor de diez mil extranjeros se encuentran en esta situación. 
en que se contaban 40.903 extranjeros, cuando se experimenta un crecimiento continuo, con una ligera inflexión durante el año 2006 como consecuencia de los procesos administrativos que afectan al padrón y que se visibilizan por vez primera en el padrón de 1 de enero de 2007. La modificación de la Ley de extranjería de 2003 incluye una disposición que regula la inscripción en el padrón de los extranjeros extracomunitarios sin permiso permanente de residencia, que deben renovar su inscripción de forma bianual. La finalidad es controlar un posible sobrerregistro de esta fuente motivada por la dificultad de conocer el retorno o la migración a países terceros. Esta corrección se computa por primera vez en enero de 2007 (Sanahuja, 2007), aunque el registro del padrón muestra que el número de extranjeros con menos de un año de residencia era similar al de años anteriores ${ }^{6}$, elemento que muestra la prolongación de la tendencia precedente en términos de flujos migratorios.

Los datos publicados recientemente para el año 2010 indican por primera vez un lento descenso de los empadronados extranjeros (282.794, con el mismo porcentaje que el año anterior, 17,5\%), lo cual rompe con la dinámica de los

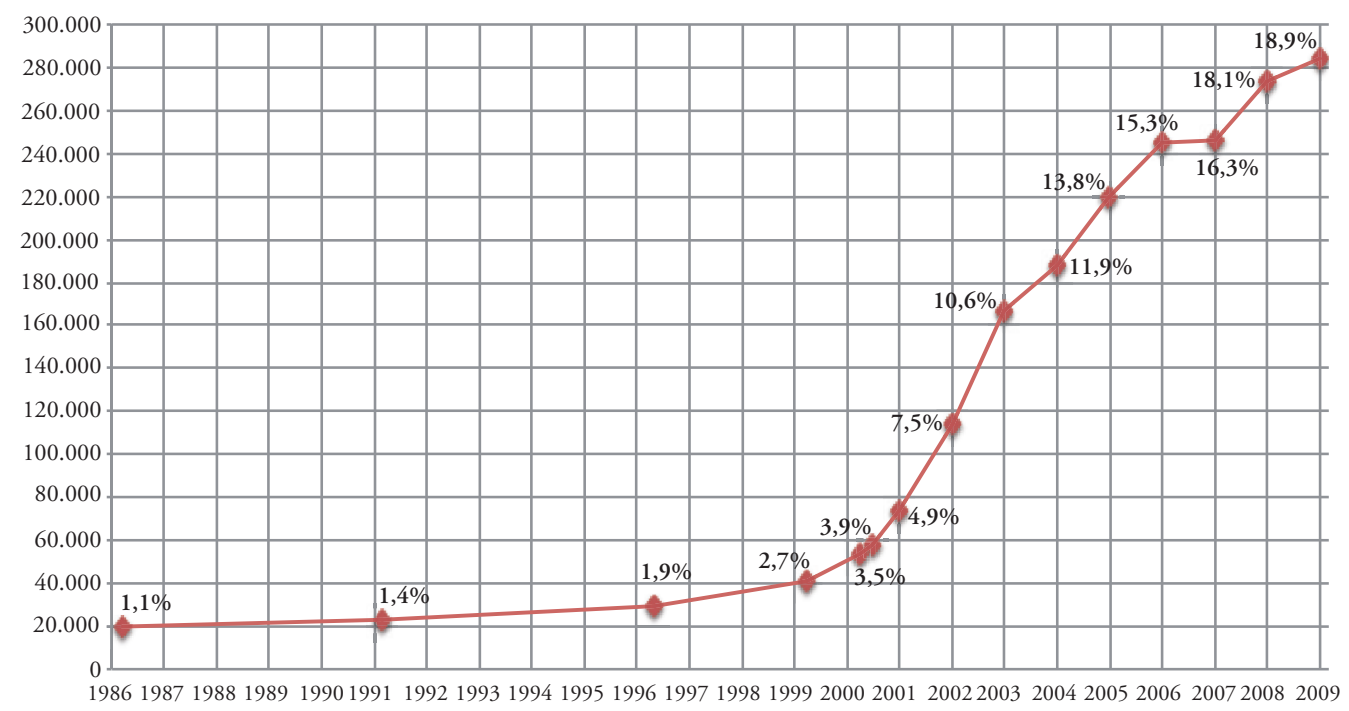

Figura 1. Evolución de la población de nacionalidad extranjera en Barcelona (meses de enero de 1986 a 2009).

Fuente: Censos y padrones de población, con datos del Departamento de Estadística del Ayuntamiento de Barcelona y del Instituto Nacional de Estadística (INE).

6. En la web del Departamento de Estadística del Ayuntamiento de Barcelona (www.bcn.es/ estadistica), se publican los datos provisionales del padrón continuo, sin las correcciones del INE: en 2006, aparecen 64.095 extranjeros registrados durante el año anterior y, en 2007, esta cifra asciende a 73.201. En contra de lo que sugiere la cifra total de empadronados, pues, el ritmo de incorporación a la ciudad no disminuye. No se dispone de esta información a partir de 2007. 
últimos años. De esta forma, y como consecuencia de la crisis económica, podría darse ya como finalizado el boom migratorio. Debido al desfase en contabilizar las bajas por caducidad de los extranjeros, es posible que esta tendencia decreciente aumente en los próximos años, con independencia de la evolución económica.

a) Absolutos

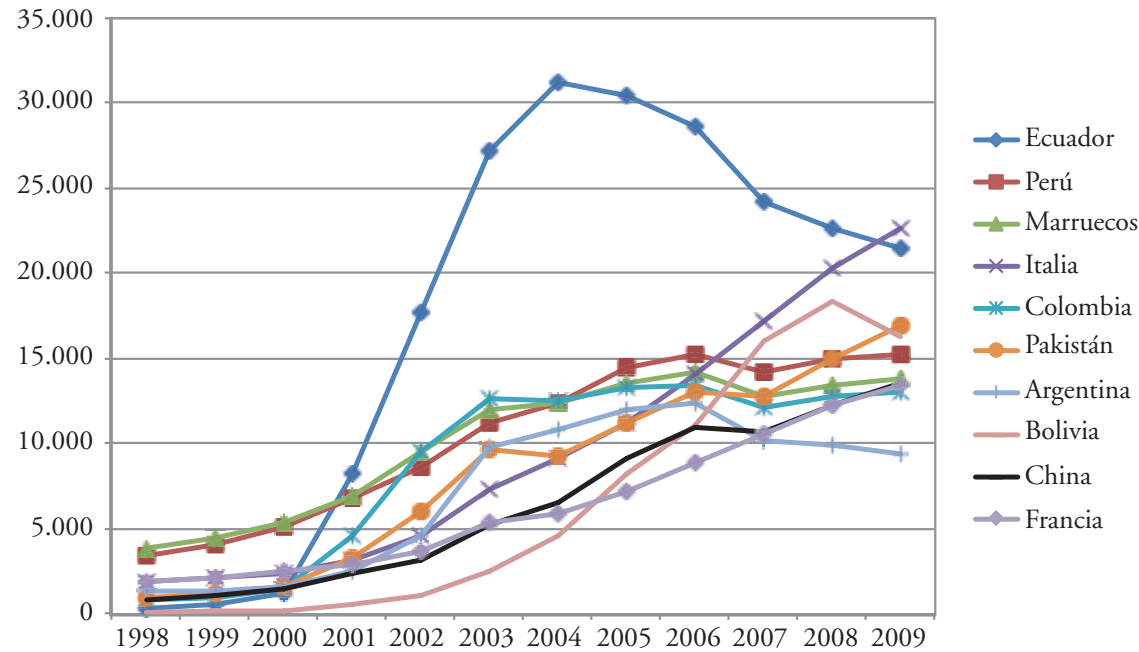

b) $r(\%)$

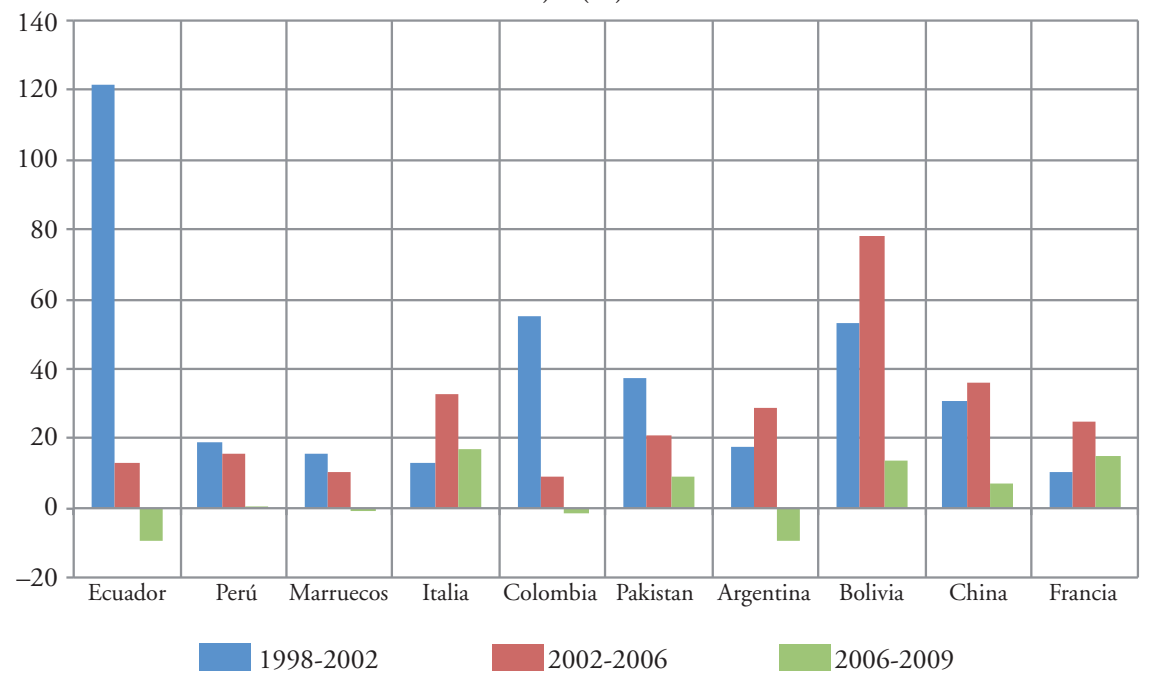

Figura 2. Evolución de las diez nacionalidades extranjeras más numerosas en Barcelona (19982009), en números absolutos (a) y tasa de crecimiento anual acumulativo (b).

Fuente: Padrón continuo de población, 1998-2009 (INE). 
Además del crecimiento del colectivo extranjero a lo largo de la década, destaca la alta variabilidad en los orígenes nacionales de los inmigrantes presentes en la ciudad: en 2009, nueve nacionalidades superaban los 10.000 residentes empadronados (figura 2a). Una tercera característica se suma a esta descripción: la diversidad en sus perfiles demográficos. Se observan nacionalidades notablemente masculinizadas (es el caso de muchas nacionalidades africanas y asiáticas, a excepción de los filipinos. En el caso de los pakistaníes, el 87,6\% de la población son hombres), mientras que en otras la presencia femenina es superior (bolivianos y paraguayos presentan un $60 \%$ y un $66 \%$ de mujeres, respectivamente, con una elevada proporción de ellas en estadios iniciales del proceso migratorio). En cambio, las diferencias entre los grandes grupos de edades son menores, ya que la mayoría han llegado recientemente a la ciudad y presentan un perfil en el que predominan los adultos jóvenes, en contraste con el envejecimiento que caracteriza a sus habitantes españoles ${ }^{7}$.

Los ecuatorianos fueron, desde 2001, la principal nacionalidad extranjera en Barcelona, aunque en 2009 han sido superados por los italianos. Entre 2000 y 2002, llegaron a multiplicar sus efectivos por catorce, consecuencia de un proceso de migración acelerado, aunque en 2004 alcanzaron un máximo que ha descendido constantemente. Entre 1998 y 2002, el crecimiento es acelerado para la mayoría de nacionalidades, un aumento que incluso se intensifica entre 2002 y 2006 para cinco de éstas, y que siempre disminuye en el último periodo considerado hasta alcanzar, incluso, valores negativos en cinco de las diez nacionalidades más numerosas en la ciudad (figura $2 \mathrm{~b}$ ). Este decrecimiento puede ser originado por posibles retornos, pero cabe sopesar la posibilidad de nacionalizaciones (entre latinoamericanos, después de dos años de residencia legal continuada) y el crecimiento de las migraciones suburbanas, que adquieren una significancia relevante en los últimos años. La difícil corrección de las bajas para los italianos, además del porcentaje elevado de nacidos en Argentina, los aúna, en 2009, como principal nacionalidad extranjera de la ciudad.

\section{La concentración y la segregación en el territorio}

En 1996, previo al boom migratorio internacional, los 29.059 extranjeros empadronados apenas representaban el 1,9\% de la población de la ciudad. Aún así, algunas secciones del municipio superaban el umbral del 20\% de extranjeros, todas ellas situadas en el casco histórico de la ciudad, en el distrito de Ciutat Vella. En contraposición, el 93,6\% de las secciones de la ciudad registraban proporciones de extranjeros por debajo del 5\%, y en muchas de ellas no se superaba el 1\%. Tan sólo algunas secciones diseminadas superaban el 5\%, que presentaban una ligera continuidad espacial en los barrios de mayor nivel económico (en los distritos de Sarrià-Sant Gervasi y Les Corts), consecuencia de un pasado reciente en el que buena parte de la inmigración residente perte-

7. En 2009, el 24,3\% de los españoles tenía más de 65 años, por un 2,1\% de los extranjeros. Entre éstos, los alemanes tenían un 7,2\% de mayores, por un 0,3\% entre los bolivianos. 
necía a países comunitarios, una situación que denotaba una fuerte polarización inicial en la distribución en función de la nacionalidad (Domingo y Bayona, 2002). El centro histórico, en cambio, experimentó, desde los años ochenta, una llegada importante de extranjeros (Aramburu, 2001), facilitada por la despoblación de unos barrios caracterizados por poseer el parque de viviendas más precario de la ciudad y unos precios bajos (Algaba, 2003), situación que, en la actualidad, se ha modificado en algunos sectores a remolque de los procesos de renovación urbana y de una incipiente gentrificación (Vilà, 2007).

A partir de 2001, el crecimiento de los flujos migratorios internacionales modifica la pauta territorial precedente, y se registra una difusión de la inmigración a todos los barrios de la ciudad, al mismo tiempo que se intensifica la concentración en el centro histórico, en el distrito de Ciutat Vella. Ese mismo año ya se observan máximos que superan el $40 \%$ de extranjeros en determinadas secciones, aunque la mayoría continúa por debajo del 5\%. En 2004, primer año con datos a nivel de sección censal del padrón, se observa ya una remarcable dispersión de la población extranjera en todo el municipio: únicamente el $12 \%$ de las secciones de la ciudad tienen menos de un 5\% de extranjeros, mientras que casi la mitad de ellas supera el 10\% (tabla 1). Destacan también los elevados porcentajes de algunas secciones de barrios periféricos de la ciudad, barrios donde la inmigración internacional era inexistente y que crecieron en los años sesenta a remolque del anterior boom migratorio que conoció la ciudad (Cabré y Muñoz, 1997; López Gay, 2008). En 2009, último dato disponible (figura 3), casi han desaparecido las secciones con menos del 5\%, y una de cada cuatro se sitúa por encima del $20 \%$. Además, continúa la dinámica de desconcentración de Ciutat Vella, al mismo tiempo que crece la concentración en barrios periféricos: 18 de las 57 secciones que superan el 40\% de extranjeros

Tabla 1. Secciones de la ciudad de Barcelona según la proporción de residentes extranjeros

\begin{tabular}{|c|c|c|c|c|c|c|c|c|}
\hline & \multicolumn{2}{|c|}{1996} & \multicolumn{2}{|c|}{2001} & \multicolumn{2}{|c|}{2004} & \multicolumn{2}{|c|}{2009} \\
\hline & absolutos & $\%$ & absolutos & $\%$ & absolutos & $\%$ & absolutos & $\%$ \\
\hline Menos del 5\% & 1.482 & 93,7 & 720 & 48,3 & 176 & 11,9 & 24 & 1,6 \\
\hline Entre el 5 y el $10 \%$ & 73 & 4,6 & 592 & 39,7 & 605 & 40,8 & 277 & 18,7 \\
\hline Entre el 10 y el $15 \%$ & 16 & 1,0 & 100 & 6,7 & 415 & 28,0 & 468 & 31,6 \\
\hline Entre el 15 y el $20 \%$ & 7 & 0,4 & 35 & 2,3 & 145 & 9,8 & 355 & 24,0 \\
\hline Entre el 20 y el $40 \%$ & 4 & 0,3 & 41 & 2,8 & 125 & 8,4 & 299 & 20,2 \\
\hline Entre el 40 y el $60 \%$ & 0 & 0,0 & 2 & 0,1 & 17 & 1,1 & 50 & 3,4 \\
\hline \multirow[t]{2}{*}{ Más del 60\% } & 0 & 0,0 & 0 & 0,0 & 0 & 0,0 & 7 & 0,5 \\
\hline & 1.582 & 100,0 & 1.490 & 100,0 & 1.483 & 100,0 & 1.480 & 100,0 \\
\hline
\end{tabular}

Fuente: Padrón de población de 1996, censo de 2001 y padrón continuo de 2004 y 2009 (INE e Idescat). 
se encuentran fuera de Ciutat Vella, cuando en 2004 todas las secciones por encima de este porcentaje se situaban en el centro de la ciudad.

Crecimiento y dispersión han caracterizado, por tanto, la inclusión residencial de la población inmigrante en la ciudad. Crecimiento que se observa en todas las secciones, y dispersión que se encamina hacia la periferia, coincidiendo con un incremento de las salidas de Barcelona hacia los municipios
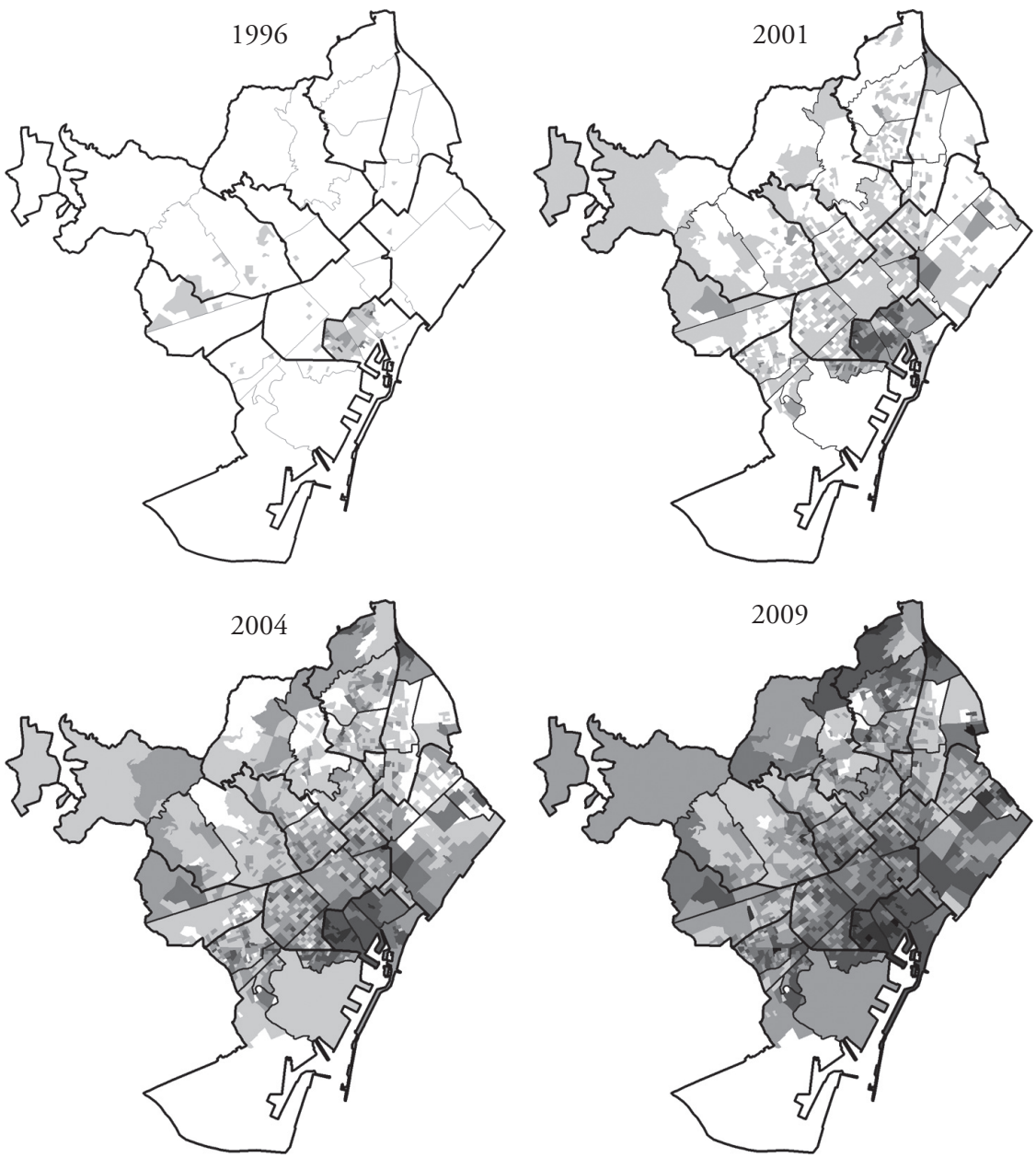

$\square$ Menos del 5\% $\square$ Entre el 10 y el 15\%
$\square$ Entre el 5\% y el 10\% $\square$ Entre el 15\% y el 20\%

Entre el 20 y el $40 \%$

Más del $60 \%$

Entre el $40 \%$ y el $60 \%$

Figura 3. Proporción de residentes extranjeros en Barcelona en 1996, 2001, 2004 y 2009. Fuente: Elaboración propia con los datos del padrón continuo de población (INE). 
limítrofes. Estos movimientos deben considerarse en relación con el mercado inmobiliario de la ciudad, que supera las fronteras municipales. El crecimiento en número de efectivos y la desconcentración territorial han sido dinámicas comunes en las nacionalidades con mayores efectivos en Barcelona, aunque en algunas de ellas la desconcentración no se haya iniciado hasta fechas muy recientes ${ }^{8}$. Esto se puede observar a partir de los índices de segregación, que muestran una dinámica decreciente para la mayoría de las nacionalidades (figura 5).

La figura 4 cartografía los cocientes de localización de las principales nacionalidades presentes en la ciudad de Barcelona para el año 2009.

El cociente de localización (QL) es una herramienta muy útil para observar la concentración de la población extranjera (Brown y Chung, 2006). Compara el porcentaje de extranjeros de una nacionalidad $\mathrm{X}$ en relación con la población $\mathrm{T}$ de una sección determinada $i$ con el porcentaje que presenta esta misma nacionalidad en el conjunto de la ciudad:

$$
Q L=\frac{\left(X_{i} / T_{i}\right)}{(X / T)}
$$

Se ha agrupado la distribución en cinco categorías diferenciadas, tres de ellas que indican sobrerrepresentación en diferentes grados (más de 4, entre 2 y 4, entre 1,2 y 2), otra donde las diferencias no son significativas (entre 0,85 y 1,2 ) y una quinta que nos indicaría subrepresentación (menos de 0,85 ).

De los casos de Francia e Italia (como también sucede en otras nacionalidades comunitarias), se deduce una fuerte presencia de secciones con altos valores de concentración, aunque pocas se sitúan en el intervalo de mayor concentración. En estos casos, domina una elevada especialización territorial, con un eje que divide a la ciudad de noroeste a sureste, desde los distritos más acomodados hasta el centro histórico, y que se extiende al barrio del Poblenou, donde se construyó la Vila Olímpica, zonas con alto nivel de renda. Esta delimitación es más clara entre los franceses que entre los italianos, que se sitúan con una pauta a medio camino entre los europeos comunitarios y los argentinos. Destaca, en comparación con años precedentes (Bayona y Blanco, 2004), una mayor presencia en Ciutat Vella, proceso ligado tanto a una incipiente gentrificación, como a la presencia de estudiantes universitarios en el centro histórico, que los registros tienden a sobrerrepresentar por la imposibilidad de actualización de los datos de los residentes comunitarios. Los pakistaníes son un caso totalmente aparte, puesto que presentan una mayor concentración territorial en Ciutat Vella y una creciente presencia en las periferias (Nou Barris y Barri Besòs), donde se reproducen altos

8. Es el caso de los filipinos, que, por su menor volumen en la ciudad, no se analizan en este texto. Éstos presentan los índices de segregación y concentración más elevados del municipio (junto con los pakistaníes), concentración que aumentaba a pesar del crecimiento de los efectivos, lo cual rompía con la pauta observada en el resto de nacionalidades. No es hasta 2005 cuando se observan los primeros signos de desconcentración. 

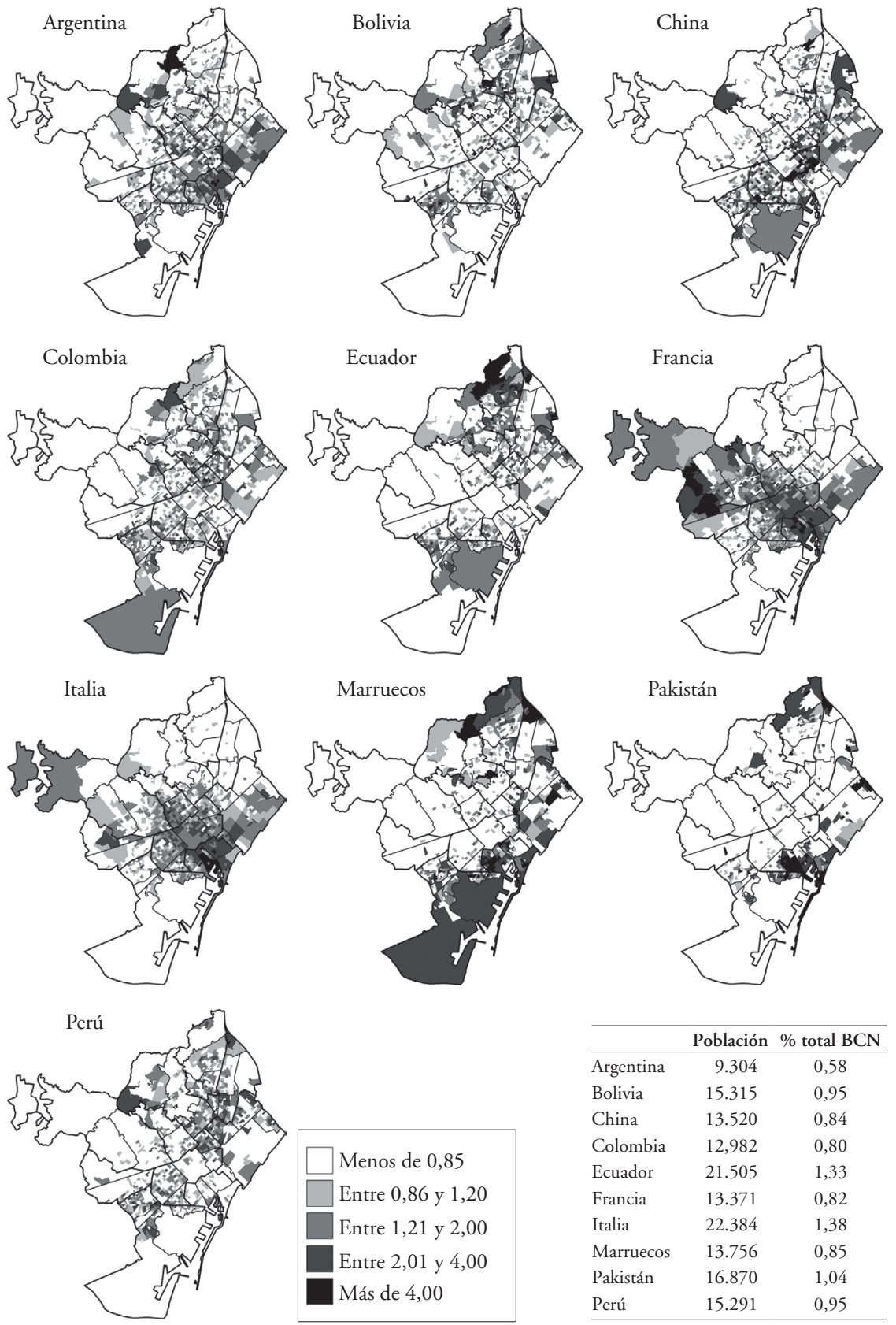

Figura 4. Cocientes de localización de las principales nacionalidades extranjeras en Barcelona en 2009, por sección censal.

Fuente: Elaboración propia. Padrón continuo de población a 1 de enero de 2009 (INE). 
niveles de concentración' ${ }^{9}$. Esta pauta, con menor intensidad, se repite en el caso de los marroquíes. Entre los chinos, se observan también unos valores altos de concentración, aunque con menor continuidad territorial. Así, ésta se observa únicamente en las zonas inferiores del Eixample, presencia ligada a su actividad comercial. En las cinco nacionalidades latinoamericanas analizadas, los argentinos muestran una pauta de concentración propia, con valores relativamente bajos pero localizados en el centro de la ciudad, mientras que las otras nacionalidades presentan una dispersión hacia las periferias cada vez mayor. Son, en general, los que registran valores de concentración más bajos, con la característica común de una presencia poco habitual en las zonas más caras y de mayores rentas de la ciudad, áreas que marcan las mayores fronteras en la distribución territorial.

La figura 5 presenta la evolución de los índices de segregación ${ }^{10}$ de las diez nacionalidades con más efectivos en la ciudad, desde 2001 hasta 2009, e incorpora al análisis la proporción de extranjeros de cada nacionalidad que vive en áreas determinadas por su cociente de localización (con las mismas categorías empleadas en la figura 4). El descenso de los indicadores es común, a excepción del caso ecuatoriano, con un punto de inflexión en el año 2006, dos años más tarde de que su población comenzara a descender. Aún así, los valores en que se mueven se encuentran por debajo de 0,4 (en una escala de 0 a 1). Para el resto de nacionalidades, cada nuevo recuento muestra una menor segregación, a pesar de que la mitad de nacionalidades pierden efectivos en el último año.

En cuanto a los valores presentados, y a excepción del caso de los bolivianos (los valores de 2001 corresponden a pocos efectivos), los marroquíes, los chinos y los pakistaníes son los que tienen índices más elevados, aunque el indicador chino ha conocido un descenso muy importante, y es en la actualidad similar al de ecuatorianos o franceses. Aunque en constante descenso, los marroquíes siguen situándose por encima de 0,5 . Pese a ser la nacionalidad con más años de antigüedad en la ciudad, parece que les cuesta conseguir unas pautas residenciales más uniformes con el resto de población. La discriminación en el acceso a la vivienda es un posible factor explicativo; no puede desdeñarse que, en las encuestas de opinión, aparecen como uno de los colectivos peor valorados por los españoles, elemento que se ha convertido en una de las mayores trabas a la integración (Gozálvez et al., 2006). El de los pakistaníes es un caso aparte, y en la explicación de su alta segregación, además de una discriminación en la vivienda, podría aparecer la voluntad de residir en un entorno más homogéneo. Los

9. En los web del Ayuntamiento de Barcelona (www.bcn.cat/estadistica/catala/terri/div84/ $\mathrm{mbcn} / \mathrm{zeg} /$ index.htm y www.bcn.cat/estadistica/catala/terri/div84/mbcn/dte/index.htm) constan las divisiones territoriales vigentes hasta 2009, que son las utilizadas en este trabajo.

10. La formulación del índice de segregación es: $I S=\frac{1}{2} \sum_{i=1}^{n}\left|\frac{x_{i}}{X}-\frac{t_{i}-x_{i}}{T-X}\right|$, donde $x_{i}$ es la población del grupo X en la unidad espacial $i$; $X$ la población del grupo X en el municipio; $t_{i}$, la población total en la unidad espacial $i$; $T$ es la población total del municipio y $n$ es el número de unidades espaciales del municipio. Este indicador es una versión del Índice de Disimilitud (Massey y Denton, 1988). 


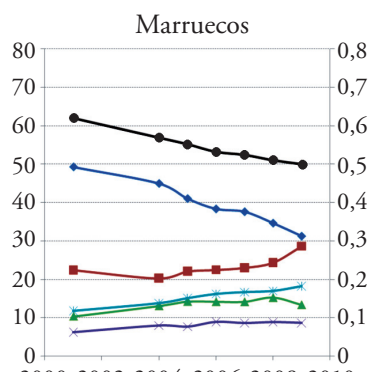

200020022004200620082010

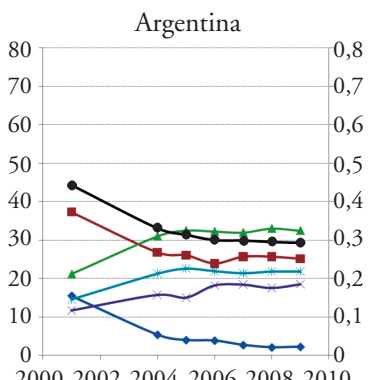

Ecuador

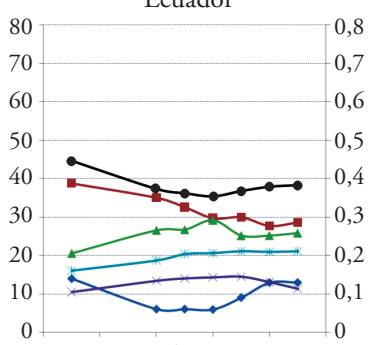

200020022004200620082010

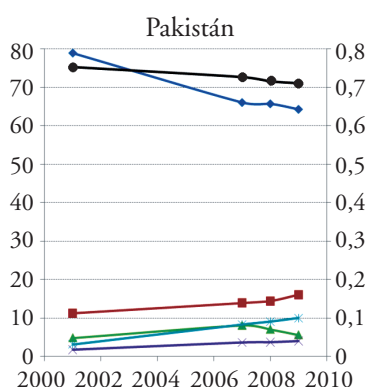

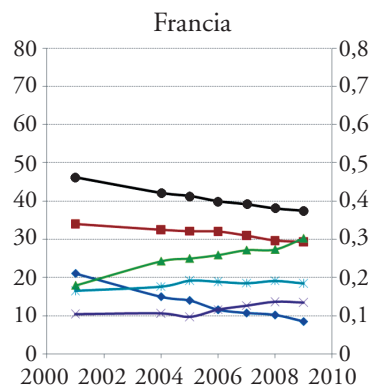

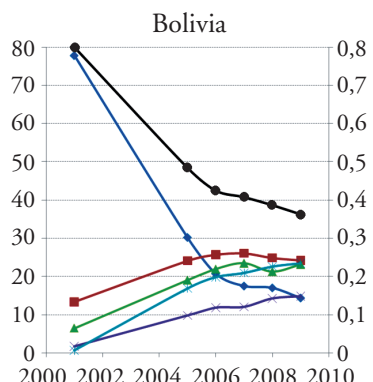

Perú

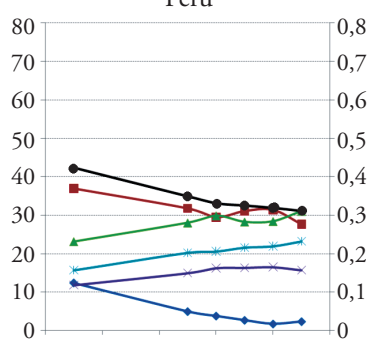

200020022004200620082010

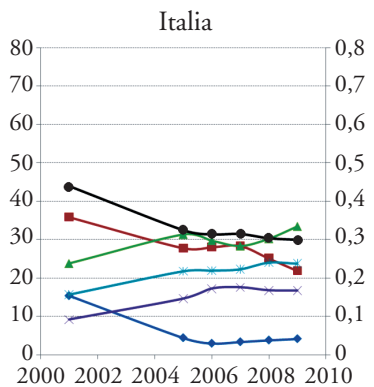

Colombia

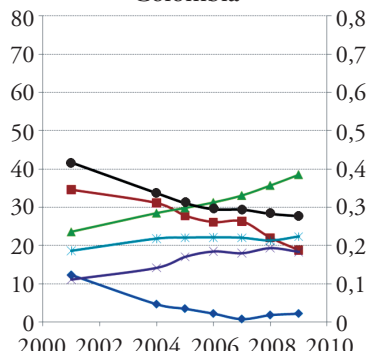

China

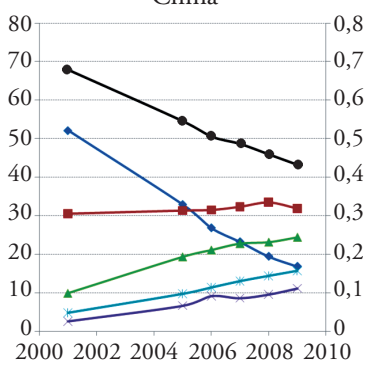

Figura 5. Evolución del índice de segregación y población según el cociente de localización, principales nacionalidades.

Fuente: Censo de población de 2001 y padrón continuo de población, varios años, con datos del INE y del Idescat. Elaboración propia.

Nota: En el eje de la izquierda, los valores se refieren al cociente de localización e indican el porcentaje de población (en \%) que se sitúa en secciones con un determinado valor. El eje de la derecha se refiere al índice de segregación (en una escala de 0 a 1). 
valores más reducidos corresponden a los casos de Italia, Perú y Colombia, alrededor de 0,3, con un descenso de 0,1 puntos entre 2001 y 2009. En cambio, los franceses muestran un registro de 0,4 , que se corresponde con una segregación socioeconómica si atendemos a las características de los barrios donde residen.

\section{La movilidad residencial de la población de nacionalidad extranjera}

La pauta de dispersión urbana de la población extranjera supera los límites de la propia ciudad y se reproduce con elevada intensidad en los municipios más cercanos a Barcelona, como se observa a partir del análisis de las migraciones internas de la población en la Región Metropolitana. Es por ello que, para realizar un análisis de las implicaciones territoriales del proceso de asentamiento de la población extranjera en el ámbito de Barcelona, es preciso superar la escala municipal e incorporar todo el espacio metropolitano. Ahora bien, este cambio de escala requiere la utilización de otra fuente de datos, la Estadística de Variaciones Residenciales, que permite aproximarse a los procesos de dispersión de la población extranjera en el territorio desde otra perspectiva analítica: nosotros proponemos la de movilidad residencial.

Como en otros aspectos demográficos, la llegada de la población extranjera a España ha modificado el patrón general de la movilidad residencial (Recaño, 2002). Primero invirtió el signo del saldo migratorio de las principales ciudades centrales, que llevaban, como en el caso de Barcelona y de Madrid, más de tres décadas presentando un signo negativo (López Gay, 2011). Poco más tarde, se identificó un comportamiento residencial que distaba del que había adoptado la población española durante los últimos años. Si éstos cambiaban poco y tarde de residencia, y cuando lo hacían, se trasladaban frecuentemente a municipios situados a cierta distancia, la población de nacionalidad extranjera cambiaba de residencia con más intensidad, presentaba diferente estructura por sexo y edad, y se relacionaba territorialmente con los ámbitos más cercanos con los que las ciudades centrales no habían compartido flujos residenciales con tanta intensidad desde hacía más de treinta años, durante la etapa de asentamiento de los antiguos migrantes interregionales (Domingo et al., 2004; Bayona y Gil, 2008; Bayona y López Gay, 2009).

Se puede considerar que la participación de la población extranjera en la movilidad residencial ha superado ya su primera etapa de emergencia. Pasados diez años de la llegada de los primeros flujos migratorios de intensidad relevante, es especialmente interesante analizar la evolución temporal de los comportamientos residenciales, con el objetivo de observar si se siguen manifestando patrones similares a los que caracterizaron a las primeras etapas del fenómeno.

\section{La participación de la población extranjera en la movilidad residencial de la ciudad de Barcelona}

La participación de la población extranjera en la movilidad residencial de Barcelona ha crecido año tras año, tanto en cifras absolutas como en cifras relativas. 
Los casi 3.500 cambios de vivienda generados en Barcelona, con destino a cualquier otro municipio español, y realizados por población extranjera representaron, en el año 2000, el 7,7\% del total de movimientos intermunicipales con origen en la ciudad. En 2002, estos desplazamientos ya representaron una cuarta parte del total, y una tercera parte en 2004. Los últimos datos de 2008 muestran más de 27.000 salidas protagonizadas por extranjeros, cifra que representa el $45 \%$ de todos los cambios de residencia originados en Barcelona (figura 6).

Paralelamente, mientras en el año 2000 la población extranjera representaba algo menos del $10 \%$ de los movimientos de entrada procedentes de otro municipio español, en 2003 alcanzó un tercio del total, y en 2008, con 23.000 entradas, estuvo cerca de representar la mitad de estos flujos. La participación de la población de nacionalidad extranjera es especialmente elevada en los movimientos con origen o destino en la propia Región Metropolitana de Barcelona (RMB), donde alcanza el 50\% de los movimientos. En cambio, en la relación con el resto de España y, especialmente, con el resto de Cataluña, la participación de población extranjera es inferior al $40 \%$.

En 2008, el número de extranjeros que abandonan la ciudad central con destino metropolitano es, por primera vez, similar al de españoles. Este dato puede ofrecer una muestra de la intensidad y del grado de redistribución de la población extranjera en el territorio metropolitano. No obstante, la evolución de ambas tendencias es divergente. Mientras la población española reduce año tras año el número absoluto de cambios intermunicipales con origen en Barcelona, la población extranjera sigue aún incrementando el número de movimientos. Barcelona no ejerce únicamente como centro redistribuidor de la población extranjera, sino que también presenta una fuerte atracción para los que residen en el resto de la RMB. El número de entradas de extranjeros procedentes de la RMB muestra una tendencia claramente al alza.

Pese a unas entradas en tendencia ascendente, el saldo migratorio de los extranjeros en su relación con la RMB sigue siendo negativo. De hecho, la pérdida de extranjeros por migración interior se produce básicamente en el contexto metropolitano. Mientras las pérdidas con el resto de la RMB suman unas 5.000 personas, en la relación con el resto de Cataluña y con el resto de España hay un equilibrio entre entradas y salidas. En 2008, incluso, el saldo migratorio relativo a estos dos ámbitos fue positivo.

El peso de la participación de la población extranjera en la movilidad residencial con origen o destino Barcelona alcanza valores máximos entre los 20 y los 25 años (figura 7). En cambio, entre los 26 y los 35 años, la representación de la población extranjera baja ligeramente, al coincidir con las edades en que la población española concentra la mayor parte de su movilidad. A partir de los 45 años de edad, la participación de los extranjeros en la migración interna desciende de forma intensa en todos los tipos de movimientos, debido a la propia estructura por edades de la población extranjera. En cuanto a la evolución de su participación en la movilidad, se observa un incremento relevante en relación con la RMB, que no se produce con la misma intensidad ni en la relación con el resto de Cataluña, ni con el resto de España. 


\section{Cambios de residencia con destino a la ciudad de Barcelona}

Con procedencia de la RMB

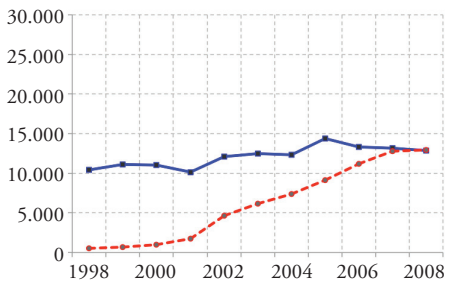

Con procedencia del resto de Cataluña

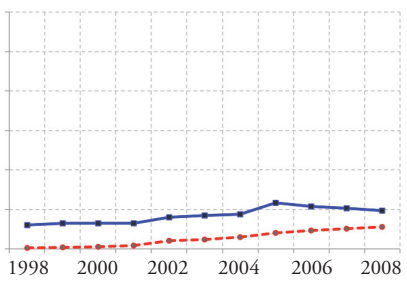

Con procedencia del resto de España

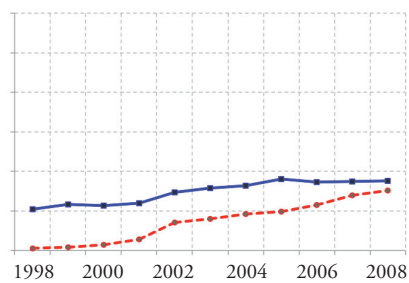

Cambios de residencia con procedencia en la ciudad de Barcelona

Con destino a la RMB

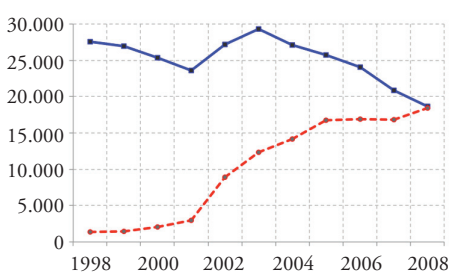

Con destino al resto de Cataluña

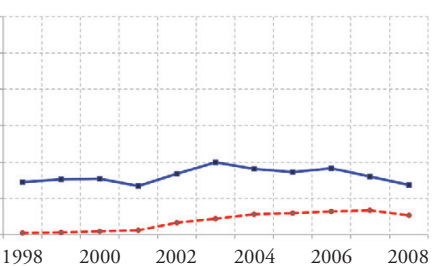

Con destino al resto de España

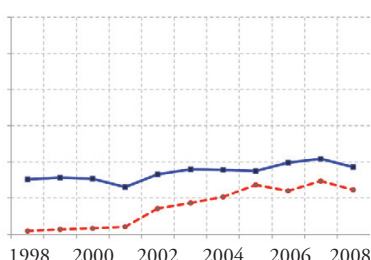

Saldo migratorio interno

En relación con la RMB

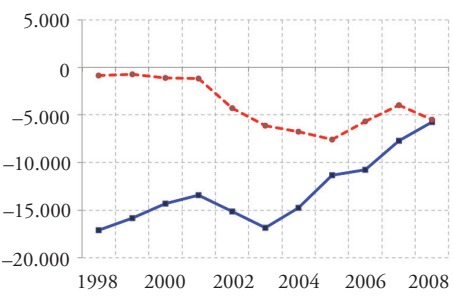

En relación con el resto de Cataluña

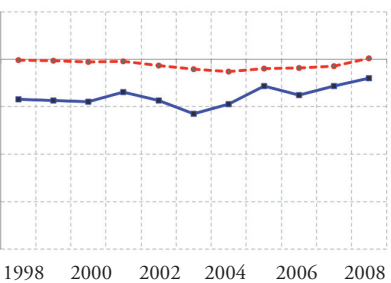

En relación con el resto de España

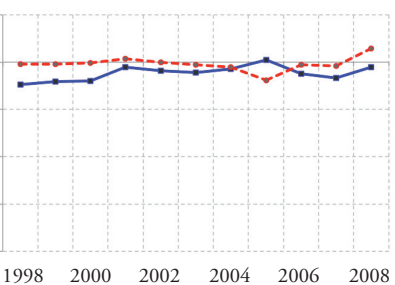

$\longrightarrow$ Nacionalidad española $\quad-\bullet-$ Nacionalidad extranjera

Figura 6. Evolución de las altas y de las bajas por migración interna con origen o destino en Barcelona según tipo de movimiento y nacionalidad (1998-2008).

Fuente: Estadística de Variaciones Residenciales, 1998-2008 (INE).

Nota: Las altas, las bajas y el saldo migratorio se muestran en datos absolutos. 


\section{Cambios de residencia con destino a la ciudad de Barcelona}

Con procedencia de la RMB

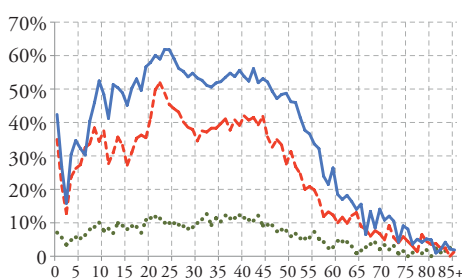

Cambios de residencia con procedencia de la ciudad de Barcelona
Con destino a la RMB

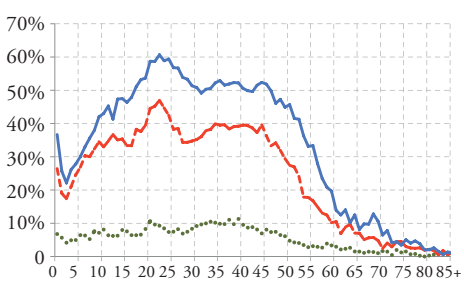

Con destino al resto de Cataluña

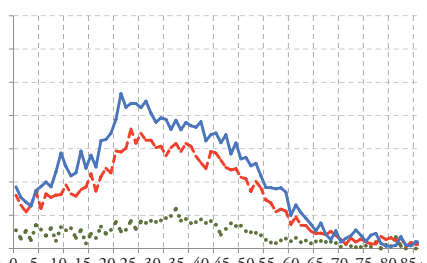

Con destino al resto de España

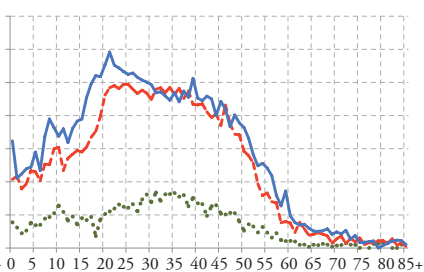

•.•1998-2001 - - 2002-2005 2006-2008

Figura 7. Proporción de extranjeros en los flujos migratorios con origen o destino en la ciudad de Barcelona, según tipo de movimiento y edad (1998-2008).

Fuente: Estadística de Variaciones Residenciales, 1998-2008 (INE).

\section{Intensidad y estructura demográfica de los flujos migratorios}

La intensidad de la movilidad residencial del conjunto de la ciudad de Barcelona ha aumentado a lo largo de la última década, sobre todo como consecuencia de la creciente participación en la dinámica residencial de la población extranjera, cada vez más móvil y más numerosa. Fruto de esta situación, la tasa bruta de movilidad residencial intermunicipa ${ }^{11}$ del conjunto de la ciudad se ha incrementado en casi un 50\% desde el periodo 1998-2001, y el indicador sintético de movilidad (ISM) ${ }^{12}$ se ha situado por encima de los tres movi-

11. La tasa bruta de movilidad residencial (TBMR) mide la intensidad anual del cambio de residencia intermunicipal, donde $C R I$ es el total anual de cambios de residencia intermunicipales y $P_{M}$ es la población a mitad de periodo:

$$
\mathrm{TBMR}=\left(\mathrm{CRI} / \mathrm{P}_{\mathrm{M}}\right) * 1000
$$

12. El índice sintético de movilidad residencial (ISMR) es un indicador de intensidad, cuyo resultado es el número de movimientos residenciales intermunicipales que realizaría una 
Tabla 2. Intensidad de la movilidad residencial intermunicipal de la población del municipio de Barcelona según nacionalidad (1998-2008)

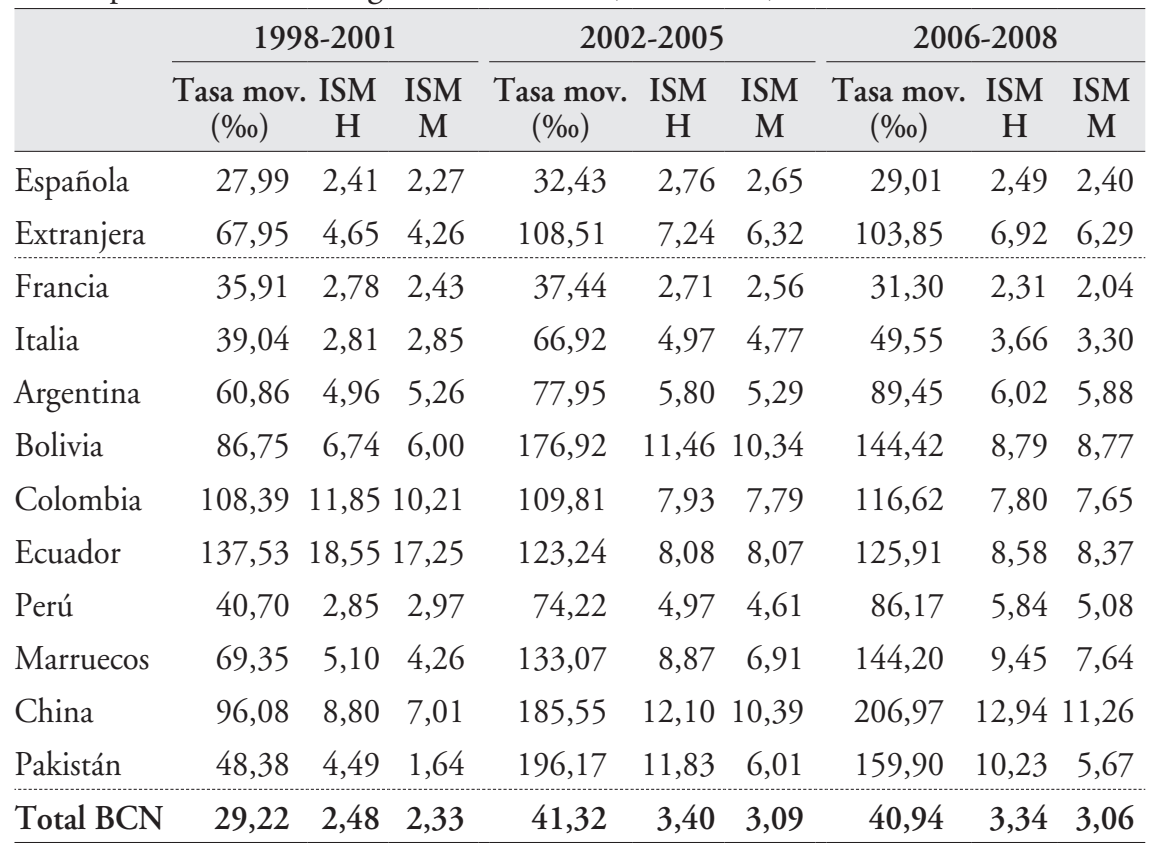

Fuente: EVR, 1998-2008, con datos del INE. Tasa mov. (\%o) es la tasa bruta de movilidad residencial. ISM es el índice sintético de movilidad residencial según el sexo.

mientos a lo largo de la vida (tabla 2). Pese a este aumento, se ha detectado un estancamiento, o incluso un ligero descenso, de los indicadores de intensidad en la segunda mitad de la década, tanto para españoles como para extranjeros.

Los indicadores muestran que los extranjeros residentes en Barcelona realizan más migraciones intermunicipales que los españoles, también una vez controlada la estructura por sexo y edad (ISM), que juega a favor de una tasa bruta más elevada para los extranjeros. La intensidad migratoria de los extranjeros multiplica por tres a la de los españoles. Mientras estos últimos realizarían alrededor de 2,5 movimientos intermunicipales a lo largo de su vida si se mantuviesen las condiciones de movilidad actuales, el conjunto de extranjeros realizaría casi siete cambios.

Entre las nacionalidades con más efectivos en Barcelona, chinos, pakistaníes y marroquíes son, por este orden, los que presentan una intensidad de

persona si las condiciones de movilidad residencial del periodo observado permaneciesen estables a lo largo de la vida: $m x$ es la tasa específica de movilidad residencial intermunicipal y $n$ es la amplitud del intervalo de edad:

$$
\operatorname{ISMR}=\sum(m x * n) / 1000
$$


la movilidad residencial más elevada (figura 8). En el periodo 2006-2008, 2 de cada 10 chinos han abandonado anualmente Barcelona, mientras que pakistaníes y marroquíes presentan una tasa bruta ligeramente inferior. Estas tres mismas nacionalidades muestran una evolución reciente específica: los chinos cambian de residencia cada vez con más intensidad, los pakistaníes han reducido la extraordinaria intensidad con la que cambiaron de residencia en 2005, mientras que la intensidad de los marroquíes es estable desde 2004. En cambio, franceses e italianos presentan una estabilidad residencial notablemente superior a la del resto de nacionalidades, aunque menor que la del conjunto de españoles.

El comportamiento residencial de los latinoamericanos se encuentra a medio camino entre la elevada inestabilidad asiática y la estabilidad europea. Es cierto, además, que en este caso existe una amplia heterogeneidad de comportamientos. Mientras argentinos y peruanos muestran una intensidad relativamente baja, colombianos, ecuatorianos y, sobre todo, bolivianos abandonan con mayor frecuencia la ciudad central. El ISM de Bolivia en 2008 se sitúa incluso por encima del de Marruecos y al mismo nivel que el de Pakistán. Entre todas las nacionalidades latinoamericanas, la única que muestra una intensidad con clara tendencia descendente es la ecuatoriana, que disminuye un $25 \%$ su ISM desde 2006. Las características demográficas del flujo residencial extranjero están fuertemente condicionadas por la estructura de la población extranjera que reside en la ciudad. Existen singularidades según la nacionalidad, pero todas coinciden en la concentración de población en edades adultas, sobre todo en los grupos más jóvenes. De esta forma, la mayor parte del flujo residencial intermunicipal extranjero está compuesto por población de 20 a 39 años.

En todas las edades, las tasas de movilidad residencial de los extranjeros son más elevadas que las de los españoles, incluso en las franjas de edad más avan-
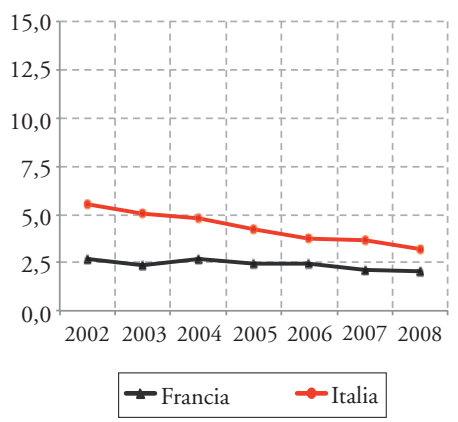

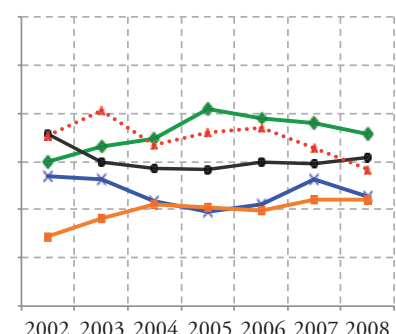

2002200320042005200620072008

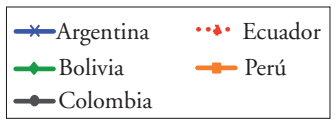

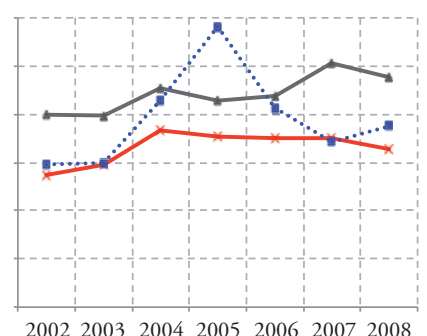

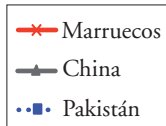

Figura 8. Evolución del Índice Sintético de Movilidad Residencial de la población de Barcelona según nacionalidad (1998-2008).

Fuente: Estadística de Variaciones Residenciales, 2002-2008, con datos del INE. 
zadas donde los efectivos extranjeros son muy reducidos (figura 9). La curva de la movilidad relativa de la población extranjera representa una ruptura con el perfil demográfico que ha caracterizado durante las últimas tres décadas a la dinámica residencial metropolitana de la población española en Barcelona. Los máximos de intensidad que registra la población española entre los 25 y los 34 años, coincidiendo con la emancipación residencial o los primeros años de convivencia, no se identifican entre la población extranjera. Entre ésta, la máxima intensidad se prolonga desde los 20 hasta los 50 años, lo cual deja entrever que, de momento, la edad no selecciona su comportamiento residencial, mientras que sí que intervienen otros elementos como la vivienda o la fragilidad de sus itinerarios residenciales, así como la llegada reciente a la ciudad. Entre los 40 y los 44 años, por ejemplo, los extranjeros se mueven cuatro veces más que los españoles.

En el último periodo analizado, 2006-2008, las tasas han disminuido tan sólo ligeramente entre los adultos de 30 a 44 años, pero no en otros grupos de edad. En este hecho probablemente intervenga el progresivo asentamiento de parte de la población extranjera, aunque no parece que el efecto sea considerable: los extranjeros continúan cambiando de residencia con una frecuencia muy elevada, a pesar de que la historia migratoria de algunos colectivos en la ciudad comienza a ser larga.

El sexo también selecciona su movilidad residencial. La intensidad de la movilidad de los hombres es superior, en casi todas las edades, a la de las mujeres (hasta los 20 años, la movilidad es similar, mientras que, a partir de los 60 años, la tasa de emigración es ligeramente superior entre las mujeres).

Población masculina

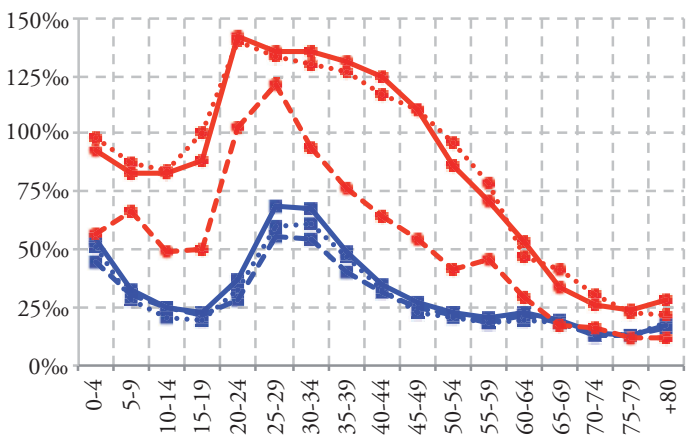

Población femenina

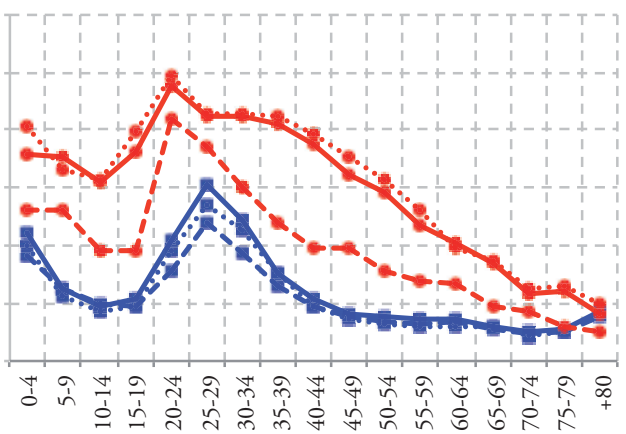

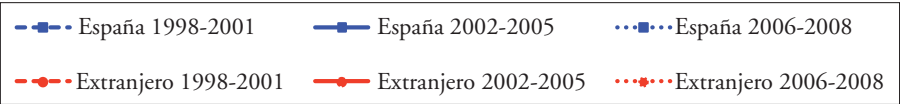

Figura 9. Estructura por sexo y edad de los flujos residenciales intermunicipales generados en la ciudad de Barcelona (1998-2008).

Fuente: Estadística de Variaciones Residenciales, 1998-2008, con datos del INE. 
Entre las nacionalidades estudiadas, destacan las diferencias de intensidad entre sexos de los marroquíes y, sobre todo, de los pakistaníes. En este último caso, la intensidad con la que los hombres cambian de residencia duplica a la de las mujeres. En estos países, son los efectivos masculinos los que protagonizan las primeras etapas del proceso migratorio (Domingo et al., 2002), por lo que las diferencias entre sexos estarían vinculadas al diferente calendario de llegada a España y a la coincidencia de la reagrupación familiar de las esposas con una etapa de mayor estabilidad residencial. En cambio, entre los latinoamericanos, la intensidad de la movilidad residencial es casi idéntica entre hombres y mujeres, equilibrio que ha permanecido muy estable a lo largo de la década. Sólo en la primera etapa de llegada, la intensidad de la movilidad residencial de los hombres bolivianos fue notablemente superior a la de las mujeres.

\section{Relaciones territoriales en la movilidad residencial de la población de nacionalidad extranjera}

Además de la mayor intensidad, la movilidad residencial de los extranjeros se caracteriza por presentar un patrón territorial que no se asemeja al de los españoles y, por lo tanto, a la movilidad que dominaba en la RMB durante las tres últimas décadas. Desde las décadas de 1960 y 1970, los municipios que limitan con Barcelona no habían recibido un flujo residencial tan elevado procedente de la ciudad central como el que están registrando desde que la población extranjera ha participado en la movilidad residencial.

En la actualidad, cuatro de cada diez cambios de residencia de extranjeros con origen en Barcelona tienen como destino alguno de los municipios localizados a menos de 10 kilómetros del centro de Barcelona (figura 10). Esta relación aumenta a casi siete movimientos si únicamente se contabilizan los que se realizan en el interior de la misma RMB (y se exceptúa, por tanto, el considerable flujo con destinación al resto de Cataluña y de España, que representa una tercera parte de todos los movimientos intermunicipales).

La población de nacionalidad española que abandona Barcelona, en cambio, localiza la nueva residencia preferentemente más allá de la primera corona metropolitana (Módenes, 1998; Pujadas, 2009). Así, mientras sólo un tercio de los movimientos intermunicipales metropolitanos de extranjeros se dirige hacia municipios localizados a más de 10 kilómetros de Barcelona, en el caso de la población española el porcentaje es superior al $75 \%$. Es por eso que el peso de la población extranjera en los movimientos que se realizan a los municipios más cercanos alcanza en las edades adultas niveles muy elevados, que se incrementan a lo largo de la década (figura 11). Entre los 20 y los 25 años, casi 8 de cada 10 movimientos residenciales con origen en Barcelona y destino a los municipios situados más cercanos es protagonizado por extranjeros. Aunque la representación en los movimientos con destino a municipios más alejados se haya incrementado, su contribución todavía es discreta, sobre todo en comparación con la importancia que tiene en los movimientos de corta distancia. En edades adultas, la población española representa aproximadamente 
dos tercios de toda la movilidad, un porcentaje que aumenta notablemente cuando se contempla a la población infantil o a la población de más de 50 años. Así, mientras en los municipios metropolitanos de la primera corona, la movilidad residencial de los extranjeros es el principal factor de crecimiento de la población (incluso por encima de las llegadas desde el extranjero), en otros sigue siendo la movilidad de los españoles la que contribuye prioritariamente al crecimiento (Bayona y Gil, 2008).

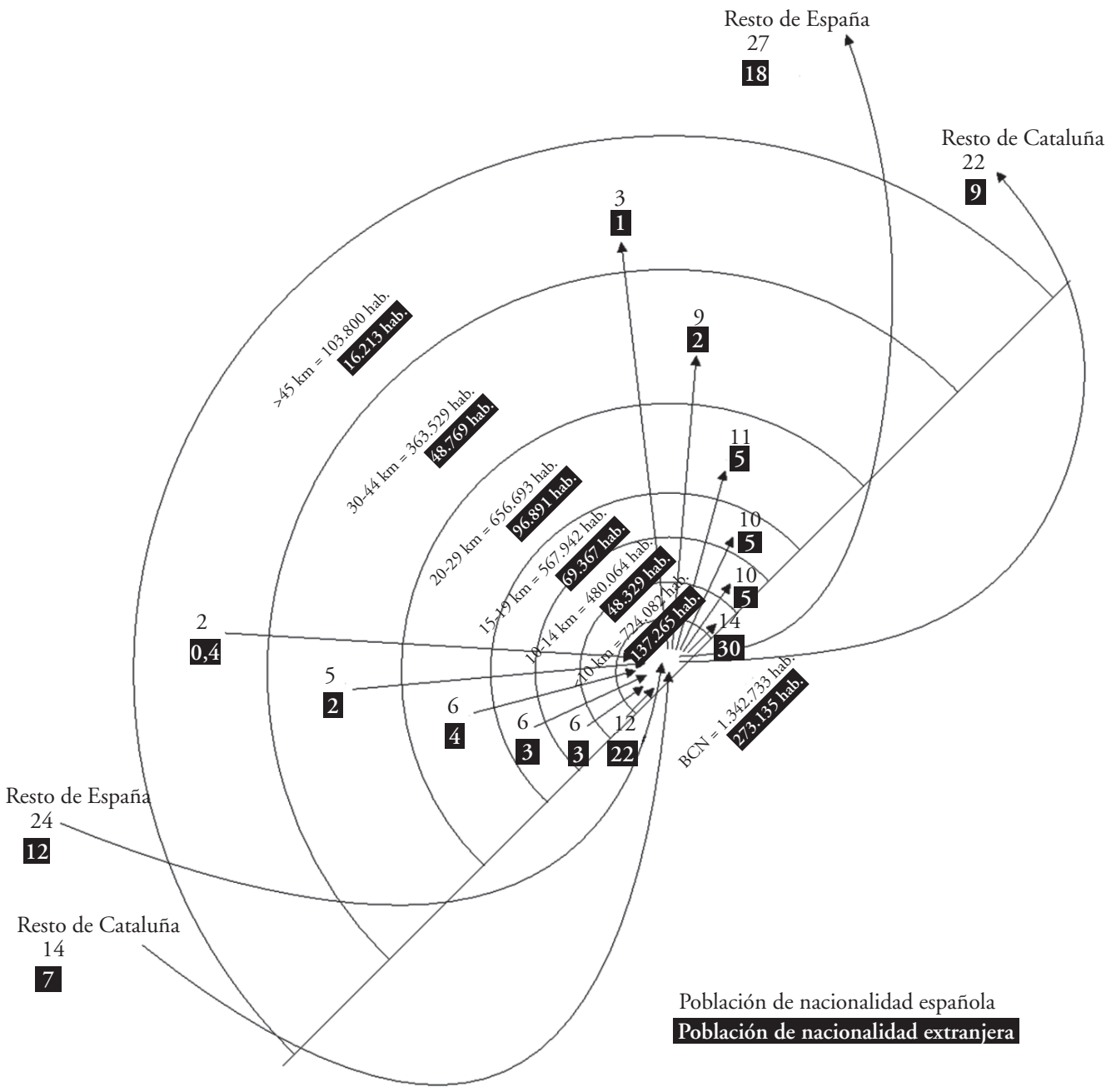

Figura 10. Flujos residenciales medios diarios de la ciudad de Barcelona con su entorno metropolitano, resto de Cataluña y resto de España según nacionalidad (2006-2008).

Fuente: Elaboración propia, EVR (2006-2008) y padrón continuo de población, 2008 (INE). 
La intensa relación que se establece en las salidas con los municipios más próximos se traslada también a los movimientos de entrada. La relación es, no obstante, menos intensa: los extranjeros protagonizan el 60\% de las entradas de población adulta de los municipios más cercanos, un porcentaje que se reduce al 35\% cuando las llegadas proceden del resto de la RMB. La EVR no permite conocer el itinerario residencial completo de los individuos, pero estos datos pueden hacer pensar que algunos de los que llegan a Barcelona podrían haber abandonado la ciudad previamente.

El proceso de asentamiento de los extranjeros y la saturación progresiva de los ámbitos más cercanos a Barcelona hicieron pensar, ya desde un principio, en un futuro en el que crecería paulatinamente la dispersión de la población extranjera por el territorio metropolitano (López Gay, 2008). En vista de los datos, parece ser que o bien ese escenario no se ha consolidado todavía (figura 12), o la ciudad de Barcelona no se encarga de ejercer ese rol. La distancia media recorrida en los cambios de residencia metropolitanos por españoles y extranjeros es todavía divergente. Mientras la población española recorre

\section{Cambios de residencia con destino a la ciudad de Barcelona}

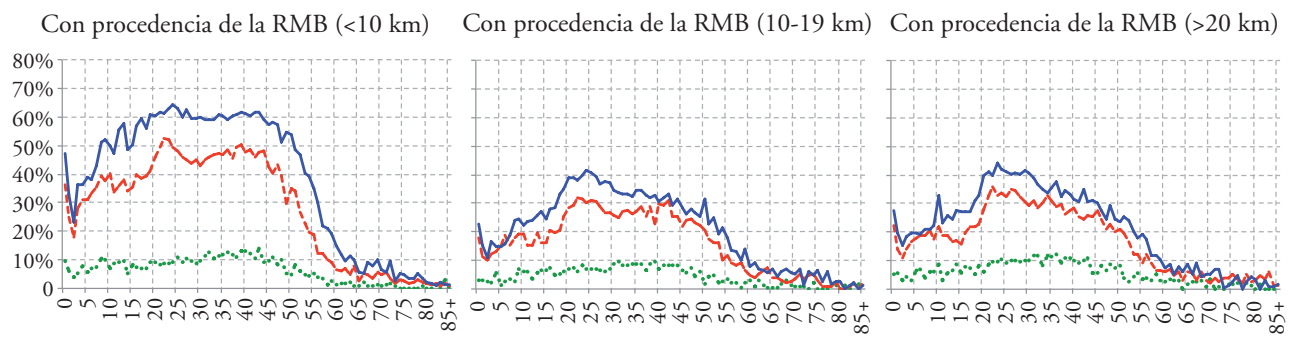

Cambios de residencia con procedencia de la ciudad de Barcelona

Con destino a la $\mathrm{RMB}(<10 \mathrm{~km}) \quad$ Con destino a la RMB $(10-19 \mathrm{~km}) \quad$ Con destino a la RMB $(>20 \mathrm{~km})$

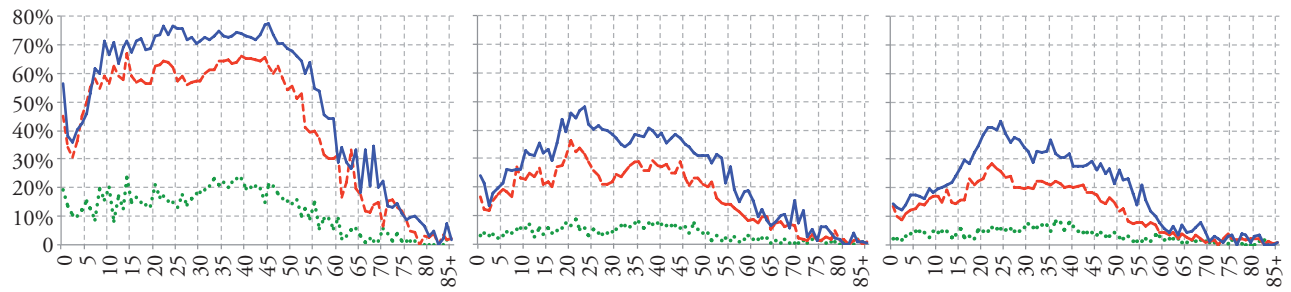

$\cdots \cdots 1998-2001--2002-2005-2006-2008$

Figura 11. Peso relativo de la población extranjera en los flujos migratorios con origen o destino en la ciudad de Barcelona, según tipo de movimiento y edad (1998-2008).

Fuente: Estadística de Variaciones Residenciales, 1998-2008, con datos del INE. 
una media de 20 kilómetros en sus migraciones de salida de Barcelona, la población extranjera se traslada a localizaciones situadas a una media de 12 kilómetros. Entre estos últimos, además, tan sólo se observa una ligerísima tendencia al alza en los últimos años, fruto principalmente del aumento de la distancia recorrida por peruanos y colombianos, únicas nacionalidades que han aumentado ligeramente la distancia media de sus desplazamientos. El resto de nacionalidades, o muestran un patrón idéntico al de los años anteriores, como es el caso de los ecuatorianos, o incluso han disminuido la distancia recorrida, como sucede entre los chinos.

Los pakistaníes muestran una preferencia extrema por la localización en los municipios más cercanos a Barcelona cuando la abandonan (figura 13). Es ésta una nacionalidad con una elevada concentración en la Ciudad Condal y, de la misma forma, cuando empiezan en 2005 a abandonar la urbe central, buscan emplazamientos muy próximos a ésta, donde reproducen pautas de concentración similar. Casi la mitad de sus cambios de residencia metropolitanos tienen como destino el municipio de Badalona; el 22,9\% se dirigen hacia Hospitalet de Llobregat, y el 11,7\%, a Santa Coloma de Gramenet (un 80\% entre los tres). Entre los chinos, también se observa una fuerte preferencia por la localización en los municipios limítrofes, aunque de una forma más moderada que entre la población pakistaní. En su caso, casi la mitad de las salidas trasladan su residencia a los municipios de Santa Coloma de Gramenet y Badalona.

Entre los latinoamericanos, los ecuatorianos y bolivianos son los que muestran una mayor preferencia por los municipios más cercanos, un patrón que se refuerza año tras año, sobre todo entre los bolivianos. En ambos casos, aproximadamente tres cuartas partes de la población que abandona Barcelona sitúa la nueva residencia en el conjunto de municipios situados a menos de 10 kilómetros. Hospitalet de Llobregat absorbe aproximadamente el $45 \%$ del
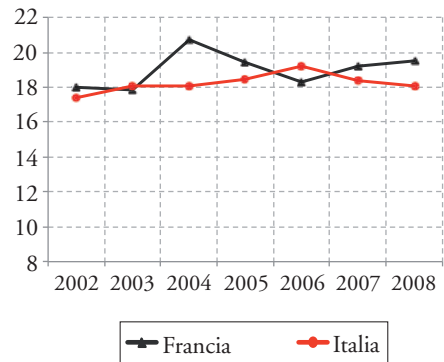
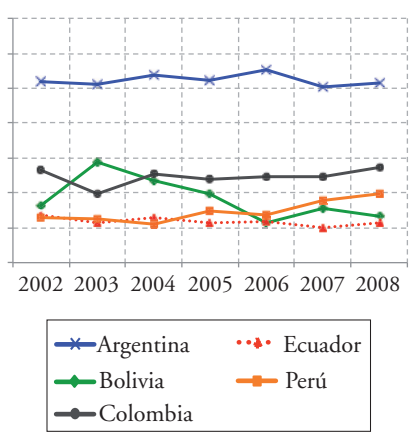
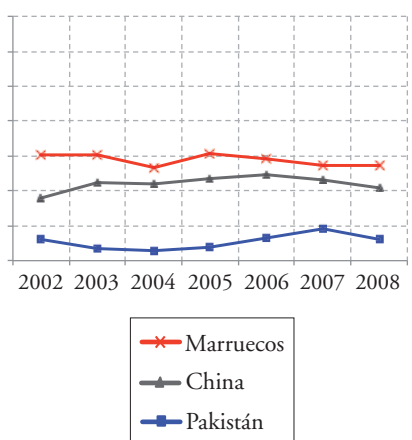

Figura 12. Evolución de la distancia media recorrida en los cambios de residencia generados en la ciudad de Barcelona y con destino a la RMB (1998-2008).

Fuente: Estadística de Variaciones Residenciales, 1998-2008, con datos del INE. 

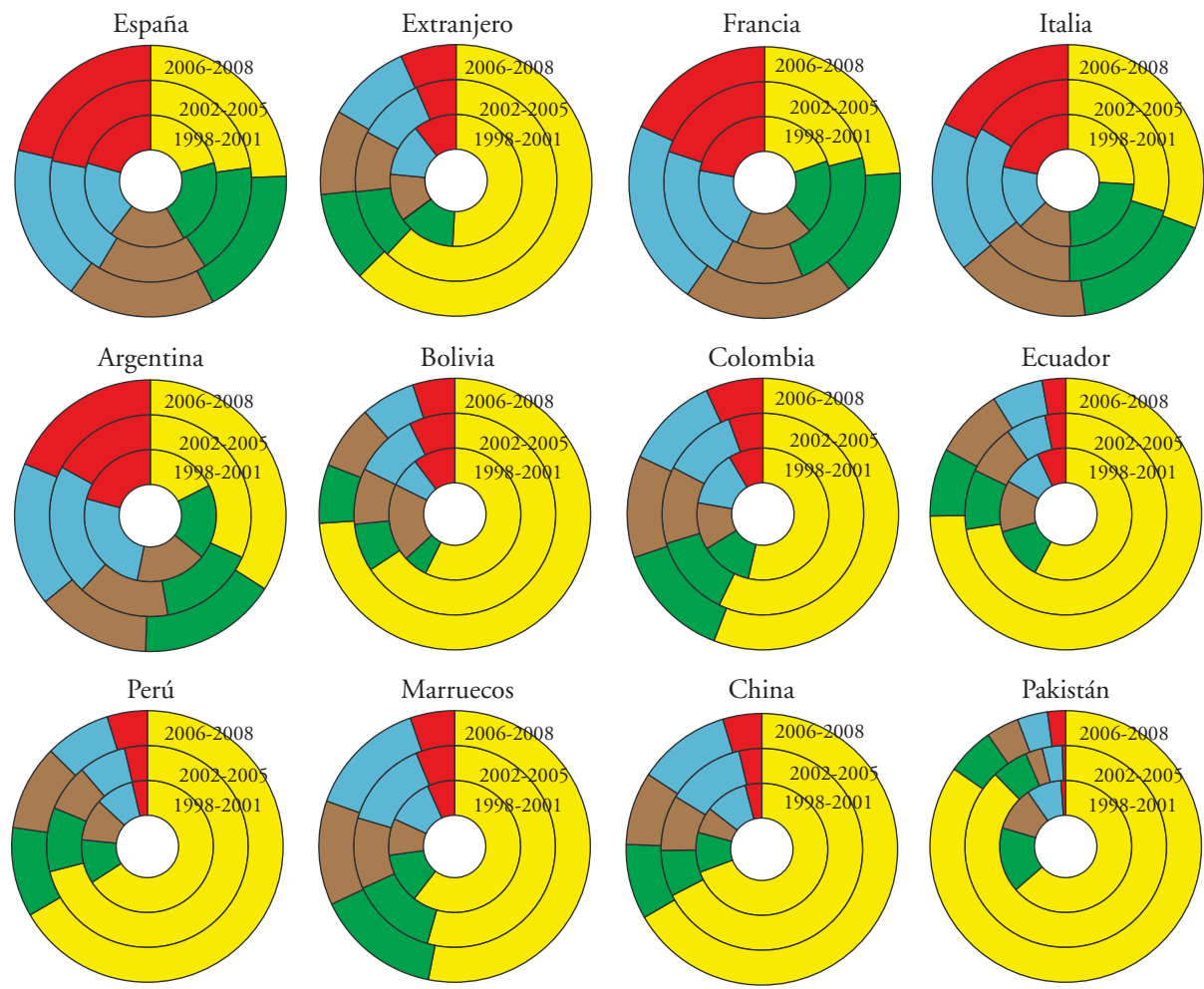

$$
\square<10 \mathrm{~km} \quad \square 10-14 \mathrm{~km} \quad \square 15-19 \mathrm{~km} \quad \square 20-29 \mathrm{~km} \quad \square>30 \mathrm{~km}
$$

Figura 13. Distribución de los cambios de residencia generados en la ciudad de Barcelona y con destino a la RMB según ámbito de destino y nacionalidad (\%).

Fuente: Estadística de Variaciones Residenciales, 1998-2008, con datos del INE.

flujo migratorio de estas nacionalidades, mientras que la suma de Santa Coloma de Gramenet y Badalona recibe una cuarta parte, de forma similar a lo que sucede entre colombianos y peruanos, aunque éstos últimos se dirigen en mayor medida a grandes municipios metropolitanos Los argentinos muestran un comportamiento divergente del resto de latinoamericanos, ya que dos terceras partes de los flujos se dirigen a municipios situados más allá de los primeros 10 kilómetros, en un patrón más similar al de los españoles.

La mitad de los marroquíes tampoco superan el límite de los 10 kilómetros, aunque tienen una presencia mayor en los municipios más alejados, con una elevada heterogeneidad de municipios de recepción, producto de su mayor dispersión en el territorio. Finalmente, los franceses e italianos muestran un patrón territorial más parecido al de los españoles de mayor renta disponible (López Gay, 2005; Pujadas y García, 2005). Su dispersión es notablemente más 
elevada que la del resto de extranjeros y recorren una media de 20 kilómetros en su cambio de residencia. Además de las principales ciudades metropolitanas, destaca su preferencia por municipios costeros y algunos interiores caracterizados por un selectivo mercado de la vivienda.

\section{Conclusiones}

La ciudad de Barcelona ha conocido, en los últimos diez años, un crecimiento explosivo de la población extranjera, que no sólo ha producido un enorme impacto en la composición por nacionalidades de su población, sino también la aparición de nuevas dinámicas residenciales. Se cumple una década de la llegada de los primeros grandes flujos migratorios internacionales y los datos existentes permiten hacer una exploración sobre la evolución en lo que respecta a su asentamiento en el territorio y a su comportamiento residencial.

Una década de observación ha sido suficiente para que se produjeran importantes cambios en la distribución de esta población. A una primera etapa de concentración en el centro histórico de la ciudad, le ha seguido un proceso consolidado de dispersión, tanto hacia los barrios más alejados del centro de la ciudad, como hacia aquellos municipios periféricos colindantes. Ambas dinámicas de dispersión creemos que deben ser interpretadas conjuntamente, ya que en las dos subyace un elemento común dentro de las estrategias residenciales de los inmigrantes. Este elemento, a nuestro entender, es la búsqueda de una vivienda más adecuada. Aunque no se haya abordado en el presente trabajo, debemos recordar que el papel que ha ejercido la vivienda, tanto en la inserción inicial en el centro histórico (constituido por un parque de viviendas antiguas y en alquiler importante), como en la dispersión hacia la periferia (con viviendas en propiedad de tamaño reducido de los años sesenta y setenta) ha sido fundamental (Algaba, 2003; Musterd y Fullaondo, 2008). Las estrategias residenciales de la población extranjera deben entenderse en el contexto de consecución de movimientos ascendentes en la escala residencial. Si, en un primer momento, fueron las características de las viviendas las que definieron su localización, con la precariedad como variable explicativa, parece probable que sea el acceso a la propiedad lo que haya dirigido a los inmigrantes a los barrios con precios más bajos, pero con elevada accesibilidad. Además, el contexto demográfico de estas zonas se caracteriza por un rápido envejecimiento de la población y que, creemos, o bien han podido rentabilizar la vivienda en propiedad para realizar un cambio residencial posterior, o bien representa la desaparición de hogares por la cúspide de la pirámide demográfica, lo cual ha alimentado el proceso de asentamiento de la población extranjera en estas zonas de la ciudad.

Pese a todo, no deja de ser interesante que las estrategias residenciales de los extranjeros les hayan permitido superar el filtro demográfico barcelonés ${ }^{13}$, que,

13. Entendemos por filtro demográfico barcelonés el mecanismo que regula la selección sociodemográfica que se ejerce sobre los flujos residenciales en los que participa el municipio 
desde hace unos años, provoca una cierta elitización de la población española que reside en la ciudad central. El resultado de estas dinámicas residenciales es una segregación con valores relativamente reducidos para la mayoría de orígenes con presencia destacable en la ciudad. Además, como en otras variables demográficas, la nacionalidad es clave para entender la heterogeneidad de comportamientos.

El abandono del municipio de Barcelona se incorporó desde etapas relativamente tempranas a las estrategias residenciales de los extranjeros, una pauta que se ha consolidado a lo largo de la década. La proximidad geográfica a las áreas con oportunidades laborales, la gestación de las redes sociales, la red de transportes públicos, la elevada accesibilidad y, sobre todo, la existencia de un mercado de la vivienda que se adapta a sus estrategias residenciales, pueden explicar el elevado atractivo de estas zonas para la población extranjera, que, recordamos, se caracterizan por una continuidad urbana con la ciudad central. La literatura sobre el tema ha contemplado la posibilidad de un escenario futuro en el que la población extranjera muestre una mayor dispersión en el territorio metropolitano. La movilidad generada en Barcelona no presenta, todavía, signos claros que permitan confirmar la llegada a esa etapa.

Estos últimos años deben, por lo tanto, considerarse bajo la perspectiva de una inusitada y elevada movilidad de los extranjeros, tanto de llegada a la ciudad, con casi setenta mil nuevas incorporaciones anuales al padrón de población, como de distribución interna, con más de cuarenta mil cambios de vivienda al año dentro de la misma ciudad, o con destino a otro municipio español, con más de cincuenta mil bajas con origen en Barcelona. El crecimiento del número de inmigrantes residentes en un barrio u otro dependía de este complejo sistema de movilidad y redistribución que ha ejercido Barcelona, y el centro histórico dentro de la ciudad, al que se suman las nacionalizaciones o las bajas con destino al extranjero, de las que poca cosa conocemos. La presencia en el territorio, medida a través de la segregación y la concentración, es producto de este enmarañado sistema de movilidad, que, debido a su intensidad, puede acarrear complejos y profundos cambios en cortos intervalos temporales. La propiedad mayoritaria de la vivienda puede frenar la velocidad de estas transformaciones, a pesar del reciente e intenso boom inmobiliario. En este sentido, el presente y el futuro más próximo obligan a prestar especial atención a la evolución a corto plazo de los procesos analizados a lo largo del presente trabajo. Por ejemplo, ¿Cómo afectará la actual crisis económica y del mercado inmobiliario en los frágiles itinerarios residenciales de los extranjeros y, por prolongación, en su segregación y concentración sobre el territorio? El cercano censo de 2011 permitirá actualizar parámetros que no se han podido analizar

central de Barcelona. Según este filtro, las personas solteras, profesionales y con un elevado nivel de estudios tienen más probabilidades de llegar a la ciudad central desde la Región Metropolitana o de permanecer en ella cuando se genera un cambio de vivienda en su interior. En cambio, los obreros manuales con un nivel de instrucción medio, en el contexto de unidades familiares ya formadas o en proceso de formación, son más propensos a abandonar el área central (López Gay, 2008). 
desde el último censo de 2001, como las características del parque de viviendas, aunque queda por ver la escala de análisis que éste permitirá, debido a su diseño muestral. Desafortunadamente, la nueva división censal de Barcelona, en vigor desde 2009, hará más compleja la comparación con los resultados obtenidos a lo largo de esta última década, caracterizada por la extraordinaria movilidad de la población extranjera.

\section{Referencias bibliográficas}

Algaba, Antonio (2003). «La discriminación en el acceso al mercado de la vivienda: las desventajas de la inmigración. Novedades y permanencias». Scripta Nova: Revista Electrónica de Geografía y Ciencias Sociales, VII, 146-160. Barcelona: Universidad de Barcelona.

Aramburu, Mikel (2001). «El mito de la "huida" autóctona. El caso de Ciutat Vella, Barcelona». Scripta Nova: Revista Electrónica de Geografia y Ciencias Sociales, 94 (63). Barcelona: Universidad de Barcelona.

Arbaci, Sonia (2004). «Southern European Multiethnic Cities and the Enduring Housing Crisis: Framing the Urban and Residential Insertion of Immigrants». ENHR Conference, Cambridge, julio.

- (2008). «(Re)Viewing Ethnic Residential Segregation in Southern European Cities: Housing and Urban Regimes as Mechanisms of Marginalisation». Housing Studies, 23 (4), 589-613.

BAYONA, Jordi (2007). «La segregación residencial de la población extranjera en Barcelona: ¿̇una segregación fragmentada?». Scripta Nova: Revista Electrónica de Geografía y Ciencias Sociales, XI (235). Barcelona: Universitat de Barcelona.

Bayona, Jordi y Blanco, Maria José (2004). «Pautes d'associació en l'espai de la població de nacionalitat estrangera a Barcelona». Documents d'Anàlisi Geogràfica, 43, 107-122.

Bayona, Jordi y GiL, Fernando (2008). «El papel de la inmigración extranjera en la expansión de las áreas urbanas. El caso de Barcelona (1998-2007)». Scripta Nova: Revista Electrónica de Geografia y Ciencias Sociales. Barcelona: Universidad de Barcelona, XII (270-132).

Bayona, Jordi y López, Antonio (2009). «La movilidad residencial de la población de nacionalidad extranjera generada en Barcelona, 2000-2004». En: Montoro, C.; López, D.; Pons, J.J. y BarCenilla, M.C. (ed.). La inmigración internacional: motor de cambios sociodemográficos y territoriales. Pamplona: EUNSA-Ediciones de la Universidad de Navarra, 101-111.

Bayona, Jordi y Pujadas, Isabel (2011). "Cambios residenciales internos en la ciudad de Barcelona: evolución y características territoriales». Investigaciones Geográficas, 52, 9-36.

Brown, Lawrence y Chung, Su-Yeun (2006). «Spatial Segregation, Segregation Indices and the geographical Perspective». Population, Space and Place, 12, 125-143.

Cabré, Anna y Muñoz, Francesc (1997). «Evolució demogràfica. La població de Barcelona, 1930-1996». Història de Barcelona, VIII. Ajuntament de Barcelona; Enciclopèdia Catalana, 107-133.

CheCA, Juan Carlos y Arjona, Ángeles (2007). «Factores explicativos de la segregación residencial de los inmigrantes en Almería». Revista Internacional de Sociología, 48, 173-200.

DíAz, Iban (2009). «Inmigración y procesos de sucesión. Hacia una nueva segregación y nuevas fronteras internas de Sevilla». En: CaravaCa, Inmaculada et al. (dir.). 
Ciudades, culturas y fronteras en un mundo en cambio. IX Coloquio de Geografía Urbana, 9-14 de junio de 2008. Sevilla: Consejería de Obras Públicas y Transportes, 328-338.

Domingo, Andreu y Bayona, Jordi (2002). «Habitatge i assentament de la població de nacionalitat estrangera als barris de Barcelona, 1991 i 2001». Qüestions d'Habitatge, 8.

Domingo, Andreu; Bayona, Jordi y Brancós, Inés (2002). Migracions internacionals $i$ població jove de nacionalitat estrangera. Barcelona: Secretaria General de Joventut, Generalitat de Catalunya.

Domingo, Andreu; Bayona, Jordi y López, Antonio (2004). «Impacto demoespacial de la internacionalización de los flujos migratorios en la ciudad de Barcelona». Migraciones, 16, 157-198.

García Almirall, Pilar; Fullaondo, Arkaitz y Frizzera, Agustín (2008). «Inmigración y espacio socio-residencial en la Región Metropolitana de Barcelona». Ciudad y Territorio: Estudios Territoriales, 158, 727-744.

GozÁlvez Pérez, Vicente et al. (2006). "Los indicadores de integración de los inmigrantes en España». En: GozÁlvez PéRez, Vicente. La inmigración extranjera como desafio y esperanza. Murcia: Universidad de Alicante.

Lavía, Cristina (2008). «La segregación residencial de la población extranjera de Bilbao». ACE: Arquitectura, Ciudad y Entorno, 8, 65-91.

López GAY, Antonio (2005). «Relaciones territoriales de la movilidad residencial de la población de Barcelona». Actas del XIX Congreso de Geógrafos Españoles. Santander.

- (2008). Canvis residencials $i$ moviments migratoris en la renovació demogràfica de Barcelona. Barcelona: Consell de Treball, Econòmic i Social de Catalunya.

- (2011). «¿Vuelve el centro?: Caracterización demográfica de los procesos de reurbanización en las metrópolis españolas». En: Pujadas, Isabel et al. (ed.). Población y espacios urbanos. Grupo de Población de la AGE; Departamento de Geografía Humana de la UB, 163-180.

Malheiros, Jorge (2002). «Ethni-cities: Residential Patterns in the Northern European and Mediterranean Metropolises-Implications for Policy Design». International Journal of Population Geography, 8, 107-134.

Martínez, A. y Leal, J. (2008). «La segregación residencial, un indicador espacial confuso en la representación de la problemática residencial de los inmigrantes económicos: el caso de la Comunidad de Madrid». ACE, 3 (53-64).

Martori, Joan Carles y Hoberg, Karen (2004). "Indicadores cuantitativos de la segregación residencial: El caso de la población inmigrante en la ciudad de Barcelona». Scripta Nova: Revista Electrónica de Geografía y Ciencias Sociales. Barcelona: Universidad de Barcelona, VIII (169).

Massey, Douglas S. y Denton, Nancy (1988). "The dimensions of Residential Segregation». Social Forces, 67 (2), 281-315.

Mateu, Jaume (2007). «Inmigración y segregación residencial en el municipio de Palma (Illes Balears), 1996-2004». En: Artigues, A. et al. (ed.). Los procesos urbanos postfordistas. Palma: Universitat de les Illes Balears - Asociación de Geógrafos Españoles, 153-180.

Musterd, Sako; Ostendorf, Wim y BreebaArt, Matthijs (1997). «Segregation in European Cities: Patterns and Policies». Tijdschrift voor Economische en Sociale Geografie, 88 (2), 182-187.

Musterd, Sako y Fullaondo, Arkaitz (2008). «Ethnic segregation and the housing market in two cities in northern and southern europe: the cases of Amsterdam and Barcelona». ACE: Arquitectura, Ciudad y Entorno, III (8), 93-115. 
Pareja-Eastaway, Montserrat (2009). "The effects of the Spanish housing system on the settlement patterns of immigrants». Tijdschrift voor Economische en Sociale Geografie, 100 (4), 519-534.

Pujadas, Isabel (2009). «Movilidad residencial y expansión urbana en la Región Metropolitana de Barcelona, 1982-2005». Scripta Nova: Revista Electrónica de Geografia y Ciencias Sociales. Barcelona: Universidad de Barcelona, XIII (290).

Pujadas, Isabel y Garcia Coll, Arlinda (2005). «Movilidad residencial y polarización social: la diferenciación social de los nuevos espacios residenciales en la región metropolitana de Barcelona». Actas del XIX Congreso de Geógrafos Españoles. Santander: Asociación de Geógrafos Españoles.

Pumares, Pablo; Garcia Coll, Arlinda y Asensio, Ángeles (2006). La movilidad laboral y goegráfica de la población extranjera en España. Madrid: Documentos del Observatorio Permanente de la Inmigración, 10. Ministerio de Trabajo y Asuntos Sociales.

ReCAÑo, Joaquín (2002). «La movilidad geográfica de la población extranjera en España: un fenómeno emergente». Cuadernos de Geografía, 72, 135-156.

Sanahuja, Ramón (2007). "La normativa d'immigració i el seu impacte a la ciutat de Barcelona». En: Larios, Maria Jesús y Nadal, Mònica (dir.). L'estat de la immigració a Catalunya. Anuari 2006. Volumen 1. Fundació Jaume Bofill, 87-108.

Torres, Francisco (2002). «Els immigrants a la ciutat de València: La inserció urbana dels nous veïns». Cuadernos de Geografía, 72, 259-288.

Vilì, Gemma (2007). "Social Effects of Urban Renewal. Gentrification in Barcelona». Comunicación presentada en la ESA 8th Confererence of the European Sociolological Association. Glasgow (CD-ROM). 